\title{
El encaje y la entrada neta de capitales: Chile en el decenio de 1990
}

\section{Guillermo Le Fort V.}

Director Ejecutivo,

Fondo Monetario Internacional glefort@ifm.org

\section{Sergio Lehmann}

Gerente de Análisis

y Operaciones Internacionales, Banco Central de Chile slehmann@bcentral.cl
Chile sufrió los efectos de una masiva entrada de capitales que se interrumpió repentinamente, a pesar de estar concentrada en flujos considerados estables, revelando así que una composición adecuada no es protección suficiente. La intensificación de las entradas estuvo asociada a factores de oferta que redujeron el diferencial entre los retornos internos y externos. El encaje contribuyó a ampliar dicho diferencial y con ello el margen de operación de la política monetaria, reduciendo además los flujos de capitales, particularmente de corto plazo, y actuando como compensación a dichos factores de oferta de financiamiento externo. Si bien la eliminación del encaje durante el período de intensificación de la afluencia de capitales habría incrementado esa afluencia, la efectividad marginal del encaje estaba acotada por la posible reducción de las entradas de corto plazo. Una estrategia más eficaz habría sido una más amplia aplicación del encaje o la complementación de la política fiscal. 


\section{I}

\section{Introducción}

La apertura irrestricta a los flujos financieros es una recomendación de política económica ortodoxa que se basa en un paralelo entre la integración comercial y la integración financiera. Sin embargo, las repetidas experiencias de crisis financieras en países en desarrollo que han abrazado la apertura financiera han abierto una importante brecha en ese paralelo. Profesores renombrados como J. Bhagwati, ${ }^{1}$ y prestigiosas revistas caracterizadas por su apego a políticas económicas liberales como The Economist (2003a y 2003b), han llamado a la revisión de la ortodoxia y a reconocer que algunas limitaciones transitorias a la integración financiera son justificadas por la experiencia práctica. El Fondo Monetario Internacional (FMI), lejos de impulsar la apertura financiera como un fin en sí, ha desarrollado en los últimos años estudios en que predominan una postura muy equilibrada respecto a los beneficios y costos de la integración financiera y recomendaciones de prudencia para avanzar en ella. ${ }^{2}$ Otros autores han realizado importantes trabajos sobre la reversión de los flujos de capitales y problemas del funcionamiento de mercados financieros como orígenes de desequilibrios macroeconómicos y costosas recesiones. ${ }^{3}$ Sus recomendaciones de política, aunque no consisten en restricciones a los flujos de capitales, implican formas de intervención pública en la libre operación de los mercados que participan de la integración financiera.

Una creciente integración financiera internacional es claramente beneficiosa sólo si es compatible con la mantención de los equilibrios macroeconómicos, incluyendo una posición sostenible de las cuentas externas. Las repentinas reversiones de los flujos de capital y las recesiones y crisis asociadas a ellas representan costos muy significativos que pueden anular los beneficios de la integración. Para mantener la sustentabilidad de la

\footnotetext{
$\square$ Agradecemos, sin comprometerlos, a Carlos Budnevich, Helmut Franken, Rodolfo Maino, Francisco Nadal de Simone y Gonzalo Sanhueza por sus valiosos comentarios, así como también a Tatiana Vargas por su eficiente asistencia. Los errores remanentes, así como las opiniones vertidas en este artículo, son de la entera y exclusiva responsabilidad de los autores, y no comprometen a las instituciones a las que pertenecen.

1 Véase Bhagwati (2003).

2 Véase Kose, Prasad y otros (2003).

3 Véase Calvo y Reinhardt (2000) y Caballero (2003).
}

posición externa de la economía, es indispensable que el crecimiento tendencial de la demanda agregada interna sea consistente con el ritmo de crecimiento del producto interno bruto (PIB) potencial, para de esta forma estabilizar el déficit en cuenta corriente en un rango sostenible, previniendo fuertes reversiones en el financiamiento externo. ${ }^{4}$

Desde 1990 y hasta 1997 inclusive, el flujo neto de capitales externos hacia Chile fue extraordinariamente elevado y estuvo por encima del financiamiento externo estimado como sostenible. En el mismo período el gasto privado real, que representa más de $75 \%$ de la demanda agregada interna, se duplicó gracias a un crecimiento medio de $10 \%$ anual, superando el ritmo de incremento del gasto público y también del producto efectivo y potencial. Este acelerado aumento del gasto fue impulsado en parte por el crecimiento del ingreso nacional, que se expandió en torno a $8 \%$ anual, en parte por los favorables términos del intercambio, y también por la fuerte entrada de capitales. ${ }^{5}$

La expansión del gasto llevó al Banco Central de Chile a aplicar una política monetaria más bien contractiva. Así, las tasas de interés real se mantuvieron elevadas y mostraron una tendencia a subir, por lo que estas no pueden ser el origen de la explosión de gasto privado. En efecto, la tasa de colocación real a 90 días promedió 8,8\% en el período 1990-1997, con un máximo de aproximadamente $15 \%$ en el primer trimestre de $1990 .{ }^{6}$ Dado que fue el gasto privado el que se sobreexpandió, no es posible atribuir el episodio expansivo a la política fiscal, particularmente considerando que la recaudación tributaria creció al ritmo de expansión del gasto privado. Sin embargo, la

\footnotetext{
${ }^{4}$ Mantener el saldo de la cuenta corriente en un rango sostenible evitaría ajustes precipitados de gasto ante reversiones de los flujos de capitales. El definido por las autoridades chilenas a inicios del decenio de 1990 fue, primero, un déficit de entre 3\% y 4\% del PIB y luego ajustado a un déficit de entre 3\% y 5\% del PIB. La experiencia internacional indica que hay una probabilidad elevada de que déficit superiores a 5\% del PIB terminen en ajustes abruptos (Agosin y Ffrench-Davis, 2001; Milessi Ferreti y Razin, 1996).

${ }^{5}$ Mediante un test de causalidad de Granger se encuentra evidencia de que los flujos de capital ayudan a predecir el gasto interno. Sin embargo, se rechaza la causalidad en sentido contrario.

${ }^{6}$ El dinamismo y alta rentabilidad de la economía real en la década de 1990 permitió conciliar la rápida expansión del gasto privado y las elevadas tasas de interés reales durante el período comentado.
} 
política fiscal adquirió un marcado sesgo procíclico, lo que dificultó el manejo monetario, induciendo a tasas de interés más elevadas que las que habrían sido necesarias bajo una política cíclicamente neutral. ${ }^{7}$

Como una forma de evitar que las alzas de la tasa de interés resultaran en mayores entradas de capitales externos, diluyendo el efecto del ajuste y generando presiones hacia la apreciación cambiaria, el Banco Central estableció, a partir de junio de 1991, un encaje a la entrada de capitales externos de carácter selectivo. El encaje formó parte de un sistema de regulaciones a las entradas de capitales destinadas a limitar su tamaño y a modificar su composición en favor de flujos más estables; esas regulaciones a su vez eran parte integral de un marco de políticas macroeconómicas caracterizadas por una banda reptante para el tipo de cambio, metas anuales de inflación decreciente, superávit fiscales, apertura comercial y amplio protagonismo del sector privado en la actividad económica, particularmente la inversión.

El encaje consistió en un depósito obligatorio, en moneda extranjera y no remunerado, que debía constituirse en el Banco Central en forma proporcional a ciertas entradas de capitales (la tasa fue de $30 \%$ durante casi todo el período), y que debía mantenerse durante un año. Este depósito resultaba en un encarecimiento del financiamiento externo que desincentivaba el ingreso de capitales, al menos por las vías de ingreso sujetas al mecanismo de encaje. Por su diseño el encaje afectaba fundamentalmente al endeudamiento de corto plazo. Entre 1990 y 1996, el encaje fue reforzado de diversas formas, de manera que el costo financiero que generaba se hizo máximo en el tercer trimestre de 1996 (llegó a 350 puntos base). Así, para evitar que la efectividad del encaje se deteriorara en el tiempo, se tomaron medidas para detener la elusión a traves de vías de ingreso no cubiertas, siendo la última de estas medidas introducida precisamente en dicho trimestre. ${ }^{8}$ Luego del cese de las presiones de la entrada de capitales, la tasa de encaje fue reducida a cero en dos etapas durante 1998 y posteriormente el encaje fue eliminado, junto con las otras regulaciones a los capitales externos, en 2001.

\footnotetext{
7 Aunque en 1990-1997 se mantuvo un superávit en las cuentas fiscales, en esos años la elasticidad del gasto público al ciclo del producto fue positiva y similar a la respuesta de los ingresos públicos al ciclo. Tanto el superávit como el comportamiento procíclico del gasto se revirtieron a partir de 1998, cuando se inicio un período recesivo, pero el gasto se expandió, compensando en parte la caída de la actividad.

${ }^{8}$ Véase un análisis de la cobertura del encaje y la evolución de las regulaciones en Le Fort y Sanhueza (1997).
}

El encaje constituyó una limitación a la integración financiera internacional y como cualquier medida de esa naturaleza tuvo tanto beneficios como costos. La polémica que surgió en su entorno dio origen a una amplia literatura de naturaleza empírica que busca medir sus efectos. La defensa del uso del encaje se ha basado en consideraciones de política macroeconómica, incluidas las de dar un mayor margen de operación a la política monetaria y evitar la profundización del ciclo económico que puede resultar de entradas masivas pero transitorias de capitales externos. Subyace en esto la idea de que la probabilidad de reversiones de flujos de capitales y el daño asociado a éstas son menores mientras menos intenso sea el uso del financiamiento externo. ${ }^{9}$ Por el contrario, los detractores sostienen que no fue eficaz para alcanzar sus objetivos, particularmente en cuanto a limitar el tamaño de los flujos de capitales, y que generó costos microeconómicos al dificultar a agentes locales el acceso al financiamiento y encarecer su costo.

Este artículo tiene como propósito central estudiar la efectividad macroeconómica de la aplicación en Chile del encaje en la década de 1990, pero no entra a analizar la conveniencia o no de su uso actual o futuro en Chile o en otras realidades. La eficacia del instrumento es sin duda uno de los factores principales para evaluar su aplicación futura, pero no el único, pues también son relevantes las condiciones de la oferta de financiamiento externo, la capacidad de la economía y del sistema financiero local para adaptarse a la volatilidad de los flujos de capitales, la infraestructura legal y de regulaciones en cuyo marco se aplicaría el mecanismo, así como las limitaciones regulatorias impuestas por tratados internacionales y otras. En suma, la aplicación actual del encaje es un tema diferente y con muy variadas complicaciones propias de cada caso, y no se le trata en este trabajo. Lamentablemente, la econometría con datos macroeconómicos está lejos de ser un método puramente objetivo, por más que muchos de sus practicantes actúen como si lo fuera. Las creencias previas desempeñan un papel de importancia en la especificación de los modelos. ${ }^{10}$ Los autores de este artículo estuvimos directamente involucrados

\footnotetext{
${ }^{9}$ La estrategia de política seguida en Chile, que incluye la regulación de los flujos de capitales, se presenta en Massad (1998) y en Zahler (1996). En trabajos del FMI se ha mencionado el encaje como un factor positivo para la estabilidad del sistema financiero, al generar incentivos contra la dolarización excesiva de los pasivos y la intermediación financiera. Véase Gulde-Wolf, Hoelsher y otros (2003). 10 Véase Leamer (1983).
} 
en el diseño y aplicación del encaje y medidas relacionadas, y la hipótesis nula de nuestro estudio es que el encaje fue eficaz a pesar de la existencia de vías de entrada de capitales no sujetas al gravamen, y que fueron utilizadas como vías de elusión. Hay evidencia de los efectos macroeconómicos del encaje en los ingresos netos que el Banco Central obtuvo por este medio (entre $0,2 \%$ y $0,3 \%$ del PIB) y en el diferencial sistemático de rentabilidad en favor de los activos en moneda nacional por sobre los activos en moneda extranjera que se registró en el período de aplicación del encaje.

Está claro que la efectividad del encaje no fue completa, pues de haberlo sido no se habría verificado el incremento excesivo del gasto privado y la ampliación del déficit en cuenta corriente que sufrió Chile hacia 1997. Pero efectividad incompleta no implica ineficacia del encaje. Para evaluarlo intentamos responder a las siguientes dos preguntas: i) ¿qué habría sucedido con la entrada de capitales y el gasto si la aplicación del encaje se hubiese eliminado en plena intensificación de la afluencia de capitales?, y ii) ¿podría una aplicación más intensa del encaje haber evitado el desequilibrio macroeconómico, o debía éste ser complementado con otras políticas? Como alternativa a una aplicación más intensa del encaje, se analiza una política fiscal contracíclica y una mayor flexibilidad del tipo de cam- bio, dado que la operación de la banda cambiaria se caracterizó por una continua presión en el borde inferior de ella durante todo el período de fuerte entrada de capitales.

El presente artículo se estructura en adelante de la siguiente manera. En la sección II se estudian las características de las fuertes entradas de capitales, se evalúa la naturaleza de su intensificación y se examina el papel del encaje como factor compensador de perturbaciones (shocks) derivadas de la oferta de capitales, sobre todo si el encaje ayudó a generar una cuña entre las tasas de interés internas y externas, otorgándole un margen de maniobra adicional a la política monetaria. En la sección III se estima un modelo econométrico simple, cuyo objetivo es analizar la efectividad del encaje sobre los flujos de capital netos y la demanda interna. En particular, se estudia si el encaje logró reducir los flujos de capitales, ayudando a atenuar el nivel de gasto. En la sección IV se simula el efecto de haber eliminado el encaje durante el período de intensificación de las entradas de capitales y también escenarios de ajuste para enfrentar el problema de una fuerte afluencia, incluyendo el uso más intenso del encaje apoyado por una política fiscal contracíclica. En la sección $\mathrm{V}$ se resumen los principales resultados $\mathrm{y}$ conclusiones del estudio. ${ }^{11}$

\section{II}

\section{Características de los flujos de capitales y perturbaciones externas}

La gran magnitud de la entrada neta de capitales a Chile entre 1990 y 1997 indica que en la década de 1990 hubo presiones por una entrada de capitales que tuvo efecto prolongado, pero que cesó bruscamente a partir de 1998 (cuadro 1). La afluencia total de capitales hacia Chile creció un promedio de $20 \%$ anual en el período 1990-1997, para revertirse con fuerza en los años siguientes. Mientras los flujos de corto plazo eran muy volátiles y sin una tendencia clara, el flujo de capitales de mediano y largo plazo mostró una tendencia sostenida al alza, con un crecimiento medio de alrededor de 23\% en 1990-1997; pero en 1998 y 1999 se registró una fuerte caída en la entrada neta de capitales, tanto de corto como de mediano y largo plazo, de más de 5 puntos porcentuales del PIB por año. ${ }^{12}$
Es de aceptación más o menos general que la vulnerabilidad a la interrupción del financiamiento externo es mayor mientras más concentrado se halla este en los flujos más volátiles y menos persistentes. Sin embargo, se ha comprobado que la concentración del financiamiento externo en flujos de mediano y largo plazo no garantiza la eliminación de dicho riesgo. Las presiones de la entrada de capitales que se dieron en

\footnotetext{
${ }^{11} \mathrm{El}$ apéndice A contiene una glosa de las variables utilizadas en este trabajo y el apéndice B presenta gráficos de las variables principales.

${ }^{12}$ Los capitales de corto plazo son los de más alta volatilidad y los de menor persistencia medida por el coeficiente de autocorrelación. Véase Le Fort y Lehmann (2000).
} 


\begin{tabular}{|c|c|c|c|c|c|c|}
\hline & \multicolumn{3}{|c|}{ Entradas brutas de mediano y largo plazo } & \multirow[b]{2}{*}{$\begin{array}{l}\text { Flujo neto de } \\
\text { corto plazo }\end{array}$} & \multirow[b]{2}{*}{$\begin{array}{c}\text { Salidas de } \\
\text { mediano y largo plazo }\end{array}$} & \multirow[b]{2}{*}{$\begin{array}{l}\text { Flujo neto } \\
\text { total }\end{array}$} \\
\hline & $\begin{array}{l}\text { Inversión } \\
\text { directa }\end{array}$ & $\begin{array}{l}\text { Inversión de } \\
\text { cartera }\end{array}$ & Créditos & & & \\
\hline 1990 & 2,2 & 1,2 & 7,4 & 4,0 & 5,2 & 9,6 \\
\hline 1991 & 2,7 & 0,8 & 4,1 & 1,0 & 5,8 & 1,8 \\
\hline 1992 & 2,5 & 1,1 & 3,9 & 4,5 & 4,7 & 6,7 \\
\hline 1993 & 2,9 & 2,7 & 4,4 & 2,9 & 5,9 & 7,1 \\
\hline 1995 & 5,3 & 1,9 & 5,2 & 0,4 & 10,3 & 3,5 \\
\hline 1996 & 7,2 & 2,7 & 7,8 & 0,4 & 8,4 & 7,8 \\
\hline 1997 & 7,3 & 4,8 & 8,2 & $-2,1$ & 11,5 & 9,8 \\
\hline 1998 & 7,3 & 1,8 & 8,3 & $-1,5$ & 18,7 & 4,5 \\
\hline 1999 & 14,8 & 4,7 & 6,2 & $-8,0$ & & $-1,2$ \\
\hline Promedio 1990-1997 & 5,6 & 2,2 & 5,8 & 1,7 & 6,9 & 7,3 \\
\hline
\end{tabular}

Fuente: Elaborado por los autores con datos del Banco Central de Chile.

Chile entre 1990 y 1997 estuvieron concentradas en corrientes de mediano y largo plazo y las de corto plazo fueron reducidas a un mínimo, pero aun así hubo una fuerte reversión de los flujos de capitales a partir de 1998. Incluso con un financiamiento externo sólo de mediano y largo plazo, los inversionistas con posiciones pasivas a mediano y largo plazo en moneda extranjera pueden recurrir al mercado cambiario forward o spot $t^{13}$ para cubrir parte del riesgo cambiario que enfrentan, generando así salidas de capitales de corto plazo, derivadas de pasivos externos de mediano y largo plazo.

\section{Intensificación de las entradas de capitales: ¿oferta externa o demanda interna?}

La intensificación de las entradas de capital puede tener carácter endógeno, cuando es producto de condiciones internas traducidas en una alta tasa de interés que atrae, por arbitraje, una fuerte afluencia de capitales externos. ${ }^{14}$ Las ampliaciones del diferencial de tasas generadas por cambios en las condiciones internas - por ejemplo, ajustes estructurales que elevan la rentabilidad de la inversión real y con ello la tasa de interés interna- atraen capitales. La intensificación

\footnotetext{
${ }^{13} \mathrm{El}$ mercado cambiario forward contempla operaciones en las que la entrega o transacción de monedas se realiza en una fecha futura, y en las que la contraparte opera fuera de una bolsa. El mercado cambiario spot comprende aquel en que la operación de compraventa de monedas tiene cumplimiento inmediato o hasta uno o dos días a partir de la fecha de contratación

14 Véase Kruger (1998) y Le Fort (1998).
}

endógena conlleva una correlación positiva entre la entrada de capitales y la tasa de interés interna, o entre la entrada de capitales y el spread ${ }^{15}$ de retornos entre activos internos y externos.

$$
\text { Spread }=r c 90-\left(\text { libo } 90-E \Pi^{*}+s\right)-E[T \hat{C} R]
$$

El spread de retornos esperado es medido como el diferencial entre la tasa de interés real interna y la tasa de interés real externa, corregido por las expectativas de devaluación y el margen de riesgo soberano de Chile, que se calcula sobre la base del bono del gobierno chileno emitido en abril de $1999 ;{ }^{16}$ rc 90 es la tasa de interés real para las colocaciones en pesos a 90 días; libo 90 es la tasa libor para las colocaciones en dólares a tres meses, $s$ el margen soberano de Chile, $E \Pi^{*}$ la inflación esperada externa representada por la variación en el índice de precios al por mayor de los Estados Unidos, y $E[T \hat{C} R]$ las expectativas de devaluación real. Para medir las expectativas de devaluación, se define $E[T \hat{C} R]$ como la diferencia entre el tipo de cambio real de equilibrio (Soto y Valdés, 1998) y el tipo de cambio real efectivo. Alternativamente, se define $E[T \hat{C} R] \_2$, que supone perfecto conocimiento del futuro, es decir, la devaluación esperada es igual a

\footnotetext{
15 Véase en el apéndice A la definición de spread utilizada en este trabajo.

${ }^{16}$ El margen soberano o por riesgo-país de la deuda chilena desde 1992 a 1998 se estima a través de empalmes con una serie de spreads de bonos de empresas chilenas, calculados sobre la base de bonos a 10 años de la Empresa Nacional de Electricidad (Endesa/Enersis). Para el período 1985 a 1992, se empalma con el índice de riesgo de Chile calculado por Euromoney.
} 
CUADRO 2

Chile: Correlaciones de la entrada de capitales

(1990-I a 2000-IV) ${ }^{a}$

\begin{tabular}{|c|c|c|c|}
\hline & $\begin{array}{l}\text { Spread esperado } \\
\quad \text { (spread) }\end{array}$ & $\begin{array}{l}\text { Spread efectivo } \\
\text { (spread_2) }\end{array}$ & $\begin{array}{l}\text { Tasa de interés } \\
\text { (rc90) }\end{array}$ \\
\hline Flujos netos totales (FKN) & $\begin{array}{c}-8 \% \\
(4,22)\end{array}$ & $\begin{array}{c}11 \% \\
(5,57)\end{array}$ & $\begin{array}{c}13 \% \\
(5,98)\end{array}$ \\
\hline Flujos netos de corto plazo (FKNCP) & $\begin{array}{c}28 \% \\
(0,46)\end{array}$ & $\begin{array}{l}19 \% \\
(0,48)\end{array}$ & $\begin{array}{c}7 \% \\
(0,02)\end{array}$ \\
\hline Flujos brutos de mediano y largo plazo & $\begin{array}{l}-18 \% \\
(5,10)\end{array}$ & $\begin{array}{l}-31 \% \\
(6,28)\end{array}$ & $\begin{array}{c}-9 \% \\
(7,95)\end{array}$ \\
\hline Flujos netos de mediano y largo plazo (FKM\&LP) & $\begin{array}{l}-38 \% \\
(3,76)\end{array}$ & $\begin{array}{c}-8 \% \\
(4,93)\end{array}$ & $\begin{array}{c}5 \% \\
(6,11)\end{array}$ \\
\hline
\end{tabular}

Fuente: Elaborado por los autores con datos del Banco Central de Chile.

a Las cifras entre paréntesis corresponden a estadísticos t.

la devaluación futura efectiva, y a ella se asocia el spread de retornos efectivos (spread_2).

Por el contrario, la intensificación de la afluencia de capitales puede ser de origen exógeno al arbitraje, y resultar de modificaciones en la apreciación y la inclinación a aceptar riesgos de inversionistas internacionales, que los lleva a buscar un cambio en la composición de sus carteras de activos. Con esto se alteran las condiciones de la oferta de capitales al país. Las perturbaciones exógenas se caracterizan porque las entradas de capitales se correlacionan con disminuciones en el diferencial internacional de tasas de interés. El mayor flujo de capitales significa entonces una mayor oferta de financiamiento externo y como resultado modera las tasas de interés internas y el spread.

La intensificación de las entradas de capital de mediano y largo plazo ha tenido un carácter predominantemente exógeno (cuadro 2). La correlación de las entradas brutas de capitales de mediano y largo plazo con el spread esperado y efectivo de los retornos de los activos internos y externos y con la tasa de interés interna es negativa: de $-31 \%$ con el spread efectivo, de $-18 \%$ con el spread esperado y de $-9 \%$ con la tasa interna. Más aún, en todos estos casos las correlaciones negativas son estadísticamente distintas de cero. En el caso de los flujos netos de mediano y largo plazo, la correlación es claramente negativa con el spread de retornos esperado y efectivo, aunque más marcada en el primer caso; pero es positiva, y estadísticamente no distinta de cero, con la tasa de interés real interna. El aumento de la entrada de capitales de mediano y largo plazo parece de origen exógeno y su presencia se relaciona con bajas en las tasas de interés internas y dis- minuciones en el spread esperado y efectivo de retornos internos y externos. ${ }^{17}$

Las entradas de capitales de corto plazo reflejan reacciones a la ampliación del spread de retornos, presentando respuestas de carácter endógeno al arbitraje; la correlación de este tipo de flujos con la tasa de interés interna es positiva (7\%), al igual que con el spread de los retornos esperado (28\%) y efectivo (32\%), pero en ninguno de estos casos la correlación positiva aparece como estadísticamente significativa. Es posible conjeturar que esta baja significación refleja algún efecto del aumento exógeno de la oferta de capitales sobre las corrientes de corto plazo.

La existencia de perturbaciones externas asociadas a los flujos de capitales no es una sorpresa. Existe una estrecha vinculación entre la actividad económica en Chile y las variables externas. La vía de transmisión más reconocida de esas perturbaciones es la que nace del efecto del ciclo económico mundial sobre el precio de las mercancías y sobre los términos de intercambio. Pero existe una segunda vía, que puede vincularse a perturbaciones externas asociadas con la oferta de capitales externos. En los resultados del análisis de causalidad que se presentan en el gráfico 1, las flechas señalan las direcciones de causalidad que aparecen como significativas de conformidad con el test de Granger. ${ }^{18}$ Del gráfico se desprende que la oferta

\footnotetext{
${ }^{17}$ Estos resultados obtenidos sobre la base de correlaciones simples se ven también reflejados en las regresiones múltiples que se presentan en la sección siguiente para los flujos de capitales netos totales y netos de corto plazo. El spread de retornos esperado aparece como una atracción estadísticamente significativa sólo para los flujos de corto plazo.

${ }^{18}$ El apéndice $\mathrm{C}$ presenta causalidades y correlaciones.
} 
GRAFICO 1

Chile: Diagrama de causalidades a la Granger ${ }^{\mathrm{a}}$

(1990-I a 1997-IV)

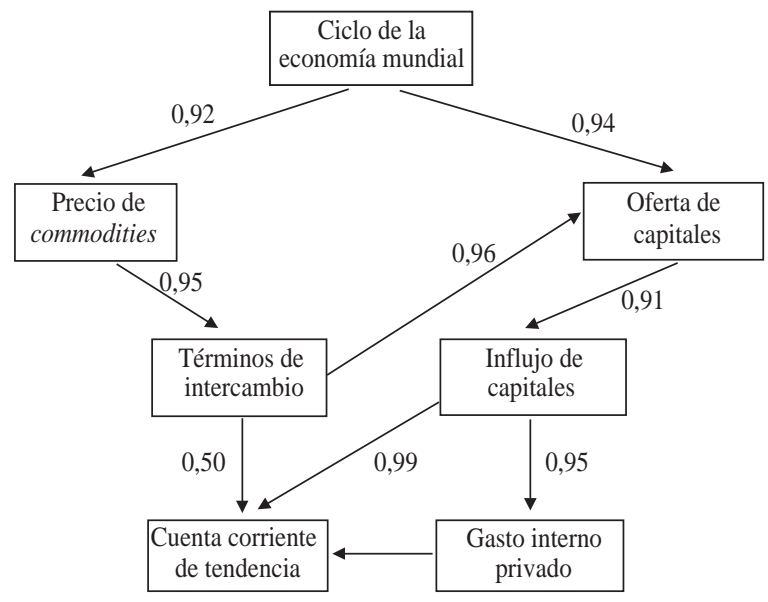

Fuente: Elaborado por los autores.

a El grado de significancia está indicado sobre las flechas.

de capitales es causada (siguiendo a Granger) por el ciclo de la economía mundial y los términos de intercambio. ${ }^{19}$ A su vez, la oferta de capitales causa la afluencia de capitales a Chile, y esta a su vez causa el gasto interno privado. ${ }^{20}$ Por último, la cuenta corriente a precios de tendencia ${ }^{21}$ es causada por el gasto privado, por la entrada de capitales y, en menor medida, por los términos de intercambio.

\section{Costo financiero del encaje, spread, tasas de interés y tipo de cambio real}

El encaje aplicado a las corrientes de capitales buscó generar un costo adicional para el financiamiento ex-

\footnotetext{
${ }^{19}$ La variable que mide la oferta de capitales externos, se define a partir de los márgenes para la deuda soberana y las corrientes netas de capitales a los principales países latinoamericanos, excluido Chile. Los flujos netos a Argentina, Brasil y México se suman ponderados por la razón entre su propio margen soberano y el chileno. De esta forma, el indicador de oferta de capitales externos a Chile se incrementa si los flujos de capitales a la región son mayores, o si el margen soberano chileno se reduce en relación con el de los otros países de la región.

${ }^{20}$ Estimaciones econométricas reconocen un quiebre estructural favorable en la oferta de capitales a partir de 1995, que estaría relacionado con avances en el desarrollo y la apertura financiera en Chile y la diferenciación de Chile del resto de las economías emergentes tras la crisis mexicana. Este quiebre se revirtió a partir de 1998.

${ }^{21}$ Véase Guajardo y Le Fort (1999).
}

terno, con miras a desalentarlo parcialmente y ampliar el radio de maniobra de la política monetaria. Esto se lograría al modificar las condiciones de arbitraje de las tasas y, por ende, el spread de retornos o sus componentes, la tasa de interés real interna o las expectativas de devaluación real. El costo financiero del encaje (CFE) se deriva de la mantención de un depósito en moneda extranjera que no paga interés y cuyo valor está determinado por la tasa de encaje, la tasa de interés externa pertinente, los impuestos a la intermediación y la moneda en que se constituye el encaje. ${ }^{22} \mathrm{El}$ encaje actúa como una cuña que aumenta el costo de obtener financiamiento externo - análogo desde el punto de vista financiero a un aumento de la tasa de interés externa- en el valor del CFE. Esta cuña, dado el mayor costo de financiamiento externo asociado, deprecia la moneda hoy y reduce las expectativas de depreciación a futuro, o bien permite aumentar la tasa de interés interna. De ambas maneras se amplía el spread de retornos esperado.

Un primer análisis empírico de los efectos del encaje consiste en examinar el posible impacto de éste sobre el spread de retornos efectivos y sobre dos variables macroeconómicas clave muy vinculadas con sus elementos componentes: la tasa de interés real interna y el tipo de cambio real. ${ }^{23} \mathrm{El}$ cuadro 3 muestra en su primera columna los resultados de un ejercicio econométrico muy simple que consiste en una regresión por mínimos cuadrados ordinarios entre el spread_2, el diferencial efectivo de retornos con una variable representativa de la oferta de capitales externos, y el costo financiero del encaje. De la estimación se desprende que este último llevó a ampliar el diferencial efectivo de retornos entre activos internos y externos mientras que la oferta de capitales externos tendió a reducirlo. El coeficiente que mide el efecto del CFE sobre el spread efectivo tiene significación al $84,5 \%$ de nivel de confianza, y no es estadísticamente distinto de uno. ${ }^{24}$ De las variables incluidas en dicha relación, el spread y la oferta de capitales externos no son integrados de orden uno.

La estimación presentada en la segunda columna del cuadro 3 parte de la misma relación de arbitraje,

\footnotetext{
${ }^{22}$ La serie de costo financiero del encaje aparece en Le Fort y Sanhueza (1997). Para más detalles véase el apéndice A.

${ }^{23}$ En el apéndice D se presenta la prueba de raíz unitaria para las variables consideradas.

${ }^{24}$ La restricción de que el parámetro asociado al CFE en la ecuación del spread es igual a 1 no es rechazada por los datos al $10 \%$ de significación, el valor del estadístico $\mathrm{F}(0,8)$, y el valor de la razón de verosimilitud $(0,8)$.
} 
CUADRO 3

Chile: Efectos del costo financiero del encaje (CFE) sobre variables de arbitraje financiero ${ }^{\mathrm{a}-\mathrm{b}}$

(1990-I - 2000-IV)

\begin{tabular}{lccc}
\hline $\begin{array}{l}\text { Variable explicada => } \\
\text { Método }\end{array}$ & $\begin{array}{c}\text { Spread_2 } \\
\text { MCO }^{\mathrm{C}}\end{array}$ & $\begin{array}{c}\text { rc90 } \\
\text { MC2E }^{\mathrm{d}}\end{array}$ & $\begin{array}{c}\text { LTCR } \\
\text { MC2E }^{\mathrm{d}}\end{array}$ \\
\hline Variables explicativas: & & & \\
Constante & 0,0799 & 0,1272 & 4,6409 \\
& $(0,224)$ & $(0,000)$ & $(0,000)$ \\
CFE + REXT-rc90 & -- & -- & 2,2624 \\
& $(--)$ & $(--)$ & $(0,006)$ \\
LDDA-LPIB & -- & -- & $-2,2657$ \\
& $(--)$ & $(--)$ & $(0,000)$ \\
CFE & 2,1826 & 0,5633 & -- \\
& $(0,157)$ & $(0,001)$ & $(--)$ \\
DUM98 & -- & 0,0093 & -- \\
& $(--)$ & $(0,011)$ & $(--)$ \\
EdTCR+REXT & -- & 0,0362 & -- \\
& $(--)$ & $(0,420)$ & $(--)$ \\
LOFCA & $-0,0163$ & $-0,0121$ & $-0,0360$ \\
& $(0,298)$ & $(0,000)$ & $(0,019)$ \\
R ${ }^{2}$ corregido & & & \\
Estadístico de & 0,0125 & 0,821 & 0,3585 \\
Durbin-Watson & & & \\
Estadístico F & 2,133 & 1,195 & 1,125 \\
\hline & 1,272 & 45,840 & 11,407 \\
\hline
\end{tabular}

Fuente: Elaborado por los autores.

a Las cifras entre paréntesis corresponden a valores $\mathrm{P}$.

b Instrumentos: CFE LFIN(-1), LOFCA FKN(-1), GAPHPY(-1), LFBKF(-1), LPIB(-1), LTI TIEMPO DUM98 rc90(-1), LIBO90 SPREAD(-1), LRSTD(-1), LGOB FKNAY(-1), LTRIB(-1), LTCR(-1), REXT EDTR(-1).

c Mínimos cuadrados ordinarios.

d Mínimos cuadrados en dos etapas.

pero deja como variable dependiente sólo la tasa de interés real interna, de manera que los otros componentes del spread - la tasa externa y las expectativas de devaluación - pasan a formar parte de las variables explicativas. En esta relación en que la tasa de interés real es la variable dependiente, las variables incluidas - salvo LOFCA - son integradas de orden uno, y la relación presentada de ellas cointegra (apéndices c y D). Se usa el método de variables instrumentales, dado que las expectativas de devaluación son endógenas. Los resultados indican que el CFE genera efectos estadísticamente significativos sobre la tasa de interés real, aunque el parámetro asociado a la tasa de interés real externa (REXT) y la devaluación real esperada (EdTCR) aparecen como no significativos, y los resultados están afectados por la autocorrelación serial. El CFE genera un efecto positivo y estadísticamente distinto de cero al $99 \%$ de nivel de confianza en la tasa de interés interna, actuando en sentido contrario a la oferta de capitales externos (medida por LOFCA o por DUM98), la que reduce significativamente la tasa de interés real interna. La variable DUM98 representa la reversión de las corrientes de capitales, es 0 durante el período de fuertes entradas y toma valor 1 a partir de 1998, cuando se produce una importante reversión de los flujos.

La estimación presentada en la tercera columna del cuadro 3 busca medir los posibles efectos que el costo financiero del encaje tendría sobre el nivel del tipo de cambio real. La estimación se controla por la oferta de capitales externos que, como se espera, reduce el nivel del tipo de cambio real, y por el exceso de demanda agregada sobre el producto, que representa el exceso de demanda de bienes asociado al déficit en cuenta corriente, el que también tiende a deprimir dicho tipo de cambio. Se muestra que el costo financiero del encaje actúa compensando uno a uno el efecto negativo que la tasa de interés interna menos la externa tiene sobre el tipo de cambio real. ${ }^{25}$ Esta tercera relación entre las variables de arbitraje, el costo del encaje y las variables de oferta de capitales aparentemente no cointegra (apéndice E).

Los resultados de las estimaciones para el spread y la tasa de interés real entregan una base empírica para defender la idea de que el encaje fue efectivo para modificar las condiciones de arbitraje internacional de tasas, otorgándole a la política monetaria algún margen de maniobra adicional. Una primera medida de ese margen se obtiene como efecto del máximo nivel del CFE (350 puntos base) sobre el spread efectivo; como se vio anteriormente, el parámetro estimado no es diferente de 1, por lo que el margen sería de hasta 350 puntos base, aunque los límites de un intervalo de confianza para él son muy amplios debido a la baja significancia del parámetro asociado. Calculando el margen de maniobra para la política monetaria sobre la base de la ecuación presentada para la tasa de interés real, el costo financiero del encaje en su punto máximo habría permitido una tasa de interés real interna más alta, de entre 90 y 300 puntos base, de acuerdo con un intervalo al $95 \%$ de confianza. Sobre la base de la ecuación para el tipo de cambio real, el nivel máximo del CFE habría otorgado un margen de maniobra a la política

\footnotetext{
${ }^{25}$ La restricción de que el parámetro asociado al costo financiero del encaje es igual al del diferencial entre la tasa de interés real externa y la interna no es rechazada por los datos (valor del estadístico F: 0,03)
} 
monetaria equivalente a un tipo de cambio real más alto en 9\%. Hay elementos empíricos para respaldar la idea de que el encaje amplió el margen de maniobra de la política monetaria, y que para hacerlo debió limitar los flujos netos de capitales. En la sección siguiente se presentan los resultados de un modelo econométrico simple que permite analizar empíricamente el efecto del encaje sobre los flujos de capitales.

\section{III}

\section{Modelo empírico para los flujos de capitales}

Diversos trabajos han abordado el estudio de los efectos del encaje sobre la afluencia de capital hacia Chile. En Forbes (2003) se presenta información sobre los costos microeconómicos del encaje para las firmas de menor tamaño, los que se habrían derivado de la cobertura parcial del gravamen y del hecho de que los flujos exentos permitían obtener financiamiento en condiciones ventajosas fundamentalmente a las firmas de mayor tamaño. En otros trabajos se midió la efectividad macroeconómica del encaje. Sin embargo, ninguno de ellos consideró la oferta de capitales externos como un factor relevante en el análisis de la intensificación de la afluencia de capital a Chile en el decenio de 1990. Entre ellos, el trabajo de Valdés y Soto (1996), por ejemplo, se concentra exclusivamente en los flujos de corto plazo, y muestra que el efecto del encaje sobre ellos ha sido negativo, pero pequeño, y que el efecto sobre el tipo de cambio real habría sido nulo. El trabajo de Chumacero, Labán y Larraín (2000), por otro lado, encuentra también un efecto negativo del encaje sobre los flujos de corto plazo y uno no significativo en los de largo plazo. El estudio de Soto (1997), asimismo, muestra un efecto del encaje sobre los flujos de capitales que es estadísticamente significativo pero carece de relevancia económica. Laurens y Cardoso (1998), por su parte, no encuentran evidencia del efecto que el encaje ha tenido sobre el flujo de capitales. Nadal-De Simone y Sorsa (1999) señalan que aún no existe evidencia respecto al efecto que el encaje ha tenido sobre la economía chilena. Tanto De Gregorio, Edwards y Valdés (2000) como Gallego, Hernández y Schmidt-Hebbel (2002) destacan que el encaje ha permitido a la economía chilena sostener un mayor diferencial de tasas de interés con el exterior, pero que su efecto sobre el tipo de cambio no es concluyente. Se acepta, no obstante, que el encaje conlleva un cambio en la composición del financiamiento, aumentando la proporción de los capitales de largo plazo.

Los resultados del presente trabajo revelan que el encaje contribuyó de manera importante a disminuir la entrada de capitales en Chile, particularmente de corto plazo, en el decenio de 1990. El estudio empírico que presentamos, a diferencia de trabajos anteriores, busca describir el efecto del encaje sobre el encuadre macroeconómico. El modelo reconoce la vinculación de la demanda privada y los flujos de capital e intenta entender el papel que le cupo al encaje en el comportamiento de estas variables en el Chile de la década de 1990. A diferencia de los trabajos empíricos anteriormente comentados, en el que presentamos a continuación se considera la oferta de capital externo como un factor relevante para explicar la afluencia de capital hacia Chile. Además de los factores de demanda de financiamiento externo que surgen a partir del déficit de la cuenta corriente impulsado por la demanda interna, el estudio abarca elementos que representan la disponibilidad de financiamiento externo, reconociendo el cambio estructural que se dio a partir de 1998, cuando los flujos de capital hacia las economías emergentes se redujeron de manera significativa.

En un trabajo nuestro anterior (Le Fort y Lehmann, 2000), intentamos medir el efecto del encaje sobre los flujos brutos de capital y de éstos sobre el gasto privado, en una especie de modelo de retroalimentación en que el encaje afecta a los flujos brutos de entrada, pero no a los de salida, y los flujos netos afectan a la demanda agregada. Esa especificación se desarrolló con las series de balanza de pagos y cuentas nacionales que tenían como año base el de 1986 y los resultados no pudieron reaplicarse satisfactoriamente en las nuevas series basadas en el año 1996. Usando las nuevas series de datos macroeconómicos, este trabajo estima funciones de comportamiento para los flujos de capitales netos y los dos principales componentes de la demanda agregada de origen privado. La causalidad va del encaje a los flujos y de éstos a la demanda agregada; pero además se reconoce el efecto de la demanda agregada sobre la demanda de financiamiento y los flujos de capital. El encaje se considera variable de política exógena, ya que parece imposible representar 
adecuadamente en una sola función de comportamiento el manejo que se hizo de este instrumento a lo largo de la década. Además, las acciones de política relativas al encaje, más que regular activamente la intensidad de este instrumento según los objetivos de política, buscaron compensar la erosión de su eficacia causada por entradas de capital no cubiertas por el gravamen.

\section{Cointegración de los flujos de capital}

En el cuadro 4 se presentan relaciones de cointegración para los flujos de capitales netos totales, para los de corto plazo y para los de mediano y largo plazo; se las estima por medio de variables instrumentales, dado lo endógeno de algunas variables explicativas. En general las variables se representan en sus logaritmos naturales, lo que se indica con una $\mathrm{L}$ antes del nombre de la variable. La excepción al uso de logaritmos fueron los flujos de capitales netos, que cambian de signo en la muestra, y las variables expresadas en tasas, como los intereses, el spread y el CFE. Los resultados de estas estimaciones cumplen con las condiciones estándares de una relación de cointegración, incluyendo la de que sus residuos son estacionarios; para cada uno de ellos se rechaza al $1 \%$ de significación la hipótesis de raíz unitaria. ${ }^{26}$

La evolución de los flujos de capital puede ser explicada razonablemente por la oferta de capitales externos, representada por: i) la variable ficticia que mide la reversión de los flujos de capitales en Chile a partir de 1998 (DUM98); ${ }^{27}$ ii) la demanda de financiamiento externo en la economía, representada por la razón entre la demanda agregada interna y el producto (LDDALPIB); iii) los términos de intercambio (LTI); iv) las variables de arbitraje; v) el diferencial de retornos esperado entre activos internos y externos (spread), y vi) el costo financiero del encaje (CFE).

Los efectos de la demanda de financiamiento externo y las condiciones de la oferta de capital exter-

\footnotetext{
${ }^{26}$ En el apéndice E se presentan pruebas de raíces unitarias de Engle y Granger para los residuos de las relaciones de cointegración.

${ }^{27}$ Dum98 es una variable ficticia con valor 0 desde el inicio de la muestra, y que toma valor 1 a partir del primer trimestre de 1998, cuando en Chile se produce una caída abrupta de las entradas de capital. Esta variable dio un mejor resultado que el índice de oferta de capitales LOFCA en la ecuación de los flujos netos totales y los de corto plazo. Usando LOFCA para representar la oferta de capital se obtienen resultados cualitativamente muy similares, pero con un ajuste más débil, como se muestra en el apéndice G. LOFCA resultó más adecuada como variable explicativa de los flujos de capital de mediano y largo plazo.
}

CUADRO 4

Chile: Estimaciones de cointegración para flujos de capital netos totales, de corto plazo y de mediano y largo plazo ${ }^{a-b}$ Método: mínimos cuadrados en dos etapas (1991-I - 2000-IV)

\begin{tabular}{lccc}
\hline Variable explicada & FKN & FKNCP & FKNMYLP \\
\hline Variables explicativas & & & \\
Constante & & & \\
& 16514,34 & 18966,37 & $-15829,91$ \\
LTI & $(0,045)$ & $(0,063)$ & $(0,097)$ \\
& $-3544,45$ & $-4205,68$ & $-2632,16$ \\
LDDA-LPIB & $(0,054)$ & $(0,061)$ & $(0,211)$ \\
& 14644,23 & 15294,07 & -- \\
Spread - CFE & $(0,001)$ & $(0,005)$ & $(--)$ \\
& 6463,43 & 17917,80 & -- \\
DUM98 & $(0,059)$ & $(0,000)$ & $(--)$ \\
& $-1508,24$ & $-1031,57$ & $-638,87$ \\
Tiempo & $(0,002)$ & $(0,003)$ & $(0,059)$ \\
& 30,39 & -- & -- \\
LOFCA & $(0,133)$ & $(--)$ & $(--)$ \\
& -- & -- & 105,5261 \\
LFBKF & $(--)$ & $(--)$ & $(0,303)$ \\
& -- & -- & 1977,47 \\
\hline R ${ }^{2}$ corregido & $(--)$ & $(--)$ & $(0,003)$ \\
Estadístico de & 0,356 & 0,143 & 0,153 \\
Durbin-Watson & 2,010 & 1,303 & 1,747 \\
Estadístico F & 7,241 & 5,029 & 3,067 \\
\hline & & & \\
\hline
\end{tabular}

Fuente: Elaborado por los autores.

a Las cifras entre paréntesis corresponden a valores $P$.

b Instrumentos: CFE LFIN(-1), LOFCA FKN(-1), GAPHPY(-1), LFBKF(-1), LPIB(-1), LTI, TIEMPO, DUM98, rc90(-1), LIBO90, $\operatorname{SPREAD}(-1)$, LRSTD(-1), LGOB, FKNAY(-1), LTRIB(-1), LTCR(-1), REXT, EDTCR(-1).

no sobre la afluencia de capitales son estadísticamente distintos de cero al $1 \%$ de significancia, y los términos de intercambio y el spread menos el CFE, casi al $5 \%$. Se incluyó además una variable de tendencia, la que captura el efecto del crecimiento económico, de la mayor integración financiera internacional y de la inflación mundial sobre los flujos de capital medidos en dólares.

La influencia individual de cada variable en los flujos de capitales está afectada por la colinealidad existente entre ellas y por lo limitado de la muestra. De hecho, el encaje se utilizó como una herramienta para tratar de compensar diferencias entre las tasas de interés interna y externa, y posiblemente tuvo algún efecto moderador de la apreciación real del peso, como se muestra en la sección anterior, por lo cual el CFE 
puede ser visto como una compensación al valor del spread. Dado lo anterior, se impuso como restricción que el efecto de este último y del cFe sobre la afluencia de capitales fuese de igual valor, pero de signo contrario. Para comprobar la efectividad del encaje sobre los flujos de capitales se volvió a estimar la ecuación de cointegración para los flujos de capital totales, con el spread y el costo financiero del encaje como variables independientes, siendo rechazada la exclusión del CFE al $5 \%$ de significancia. ${ }^{28}$

Debemos destacar, sin embargo, que el efecto negativo del costo financiero del encaje sobre los FKN depende de manera crítica de la inclusión de la variable que mide la oferta de capitales (DuM98). Si se ignora que durante el período de vigencia del encaje se dio un aumento extraordinario de la oferta de capitales y se omite DUM98 y LOFCA, el encaje aparece débilmente asociado a los flujos de capital. La inclusión de variables asociadas con el efecto de la oferta de capital se justifica plenamente dada la naturaleza del problema bajo estudio; la exclusión de Dum98 y del CFE de la ecuación de FKN es claramente rechazada por los datos al $1 \%$ de significancia (apéndice G, cuadro G2), y además deteriora notablemente el poder explicativo de la regresión para FKN; el $\mathrm{R}^{2}$ corregido cae de 0,44 a 0,14 ( apéndice G, cuadro G1).

Si descomponemos los flujos netos de capital en flujos de corto plazo (FKNCP) y de mediano y largo plazo (FKNMYLP), los resultados de la estimación para cada tipo de flujo muestra comportamientos claramente distinguibles respecto del encaje. En el caso de los flujos de corto plazo, cuya estimación se presenta en la columna (FKNCP) del cuadro 4, la respuesta al encaje es aún más pronunciada que en el caso de los flujos totales. El coeficiente del spread-CFE asociado a los FKNCP es más del doble del correspondiente a la estimación de los flujos totales y significativo al $99 \%$ de confianza.

En el caso de los flujos de mediano y largo plazo, cuyos resultados se presentan en la tercera columna del cuadro 4, ni el efecto del encaje ni el del margen fueron significativos; por lo tanto, ambas variables

\footnotetext{
${ }^{28}$ En la estimación sin restricción, el parámetro asociado al CFE en la ecuación de cointegración para las entradas de capital alcanzó a -26712 , siendo significativo al $95 \%$ de confianza; mientras que el correspondiente al spread alcanzó a 2505, no siendo significativamente distinto de cero ni al $25 \%$ de confianza. Se obtiene un estadístico $\mathrm{F}$ igual a 4,16 en el test de equivalencia para las dos configuraciones que incluyen y excluyen el costo financiero del encaje, lo cual indica que con un $95 \%$ de confianza se rechaza la hipótesis de exclusión del encaje.
}

fueron omitidas, aceptando que el arbitraje de rentabilidades no fue una fuerza dominante para impulsar los flujos de mediano y largo plazo. La evolución de FKNMYLP está más directamente relacionada con la formación de capital fijo y la evolución de las condiciones de oferta de capitales externos (LOFCA). Es de notar entonces que la efectividad del encaje para afectar las corrientes de capitales totales se encuentra fundamentalmente determinada por la respuesta de los flujos de corto plazo a esta regulación. Esto confirma los resultados anteriores referentes al efecto del encaje sobre la composición del financiamiento externo en el sentido de favorecer a los flujos de mediano y largo plazo.

\section{Modelo de corrección de errores para los flu- jos de capitales netos}

Las estimaciones de ecuaciones de corrección de errores se hacen por el método de mínimos cuadrados ordinarios. No se incluyen cambios contemporáneos en las variables endógenas del modelo y las variables rezagadas pueden ser consideradas exógenas. Para denotar la primera derivada respecto del tiempo de la variable utilizada en las estimaciones de cointegración se antepone una $\mathrm{D}$ al nombre original de la variable, mientras que el número de rezagos se expresa entre paréntesis después de la variable. Debe notarse que para aquellas variables expresadas en logaritmo (por ej., LTI), la variación del logaritmo se expresa como si se tratara de la variación de la variable original (DTI).

En los resultados de la estimación de la corrección de errores para los flujos de capital netos totales, que se presentan en la primera columna del cuadro 5, se destaca la respuesta rápida y estadísticamente significativa de los flujos de capital a los errores de la ecuación de cointegración de los FKN rezagados un período, RESIDFKN (-1). La respuesta de los flujos netos de capital totales se da respecto de variables relacionadas con el arbitraje y variables macroeconómicas. Las variables macroeconómicas incluyen la variación en los términos de intercambio (DTI) y el cambio en la demanda de financiamiento externo representado por la diferencia entre el cambio de la demanda agregada y del producto (DDDA-DPIB), y la variación en la oferta de capital externa (LOFCA), todos con diferentes rezagos. Entre las variables vinculadas al arbitraje se hallan la variación del encaje (DCFE) y la variación en la tasa de interés real externa a 90 días (DREXT), también con distintos rezagos. Todas las variables explicativas aparecen estadísticamente distintas de cero al 5\% de significancia o menos. La exclusión de las variables 
CUADRO 5

Chile: Estimaciones de corrección de errores para flujos de capital netos totales, de corto plazo y de mediano y largo plazo ${ }^{a}$ Método: mínimos cuadrados ordinarios (1991-II - 2000-IV)

\begin{tabular}{|c|c|c|c|}
\hline Variable explicada $\Rightarrow$ & DFKN & DFKNCP & DFKNMYLP \\
\hline \multicolumn{4}{|l|}{ Variables explicativas: } \\
\hline $\mathrm{C}$ & $-45,540(0,300)$ & $-89,425(0,342)$ & -- \\
\hline DCFE & -- & $-73185(0,000)$ & $44082(0,002)$ \\
\hline $\operatorname{DCFE}(-1)$ & -- & $48807(0,004)$ & -- \\
\hline $\operatorname{DCFE}(-4)$ & $-17925(0,029)$ & -- & $-44082(0,002)$ \\
\hline $\operatorname{DCFE}(-7)$ & $-24118(0,003)$ & -- & -- \\
\hline $\operatorname{DREXT}(-5)$ & $-18234(0,002)$ & $-34928(0,002)$ & -- \\
\hline $\operatorname{DREXT}(-6)$ & -- & $-32400(0,003)$ & -- \\
\hline $\operatorname{DREXT}(-1)$ & -- & -- & $-24663(0,018)$ \\
\hline DRC90(-2)-DREXT(-2) & -- & $21010(0,000)$ & -- \\
\hline DTI(-3)+DTI(-4) & $-2287,3(0,006)$ & $-2287,3(0,006)$ & $-2521,6(0,06)$ \\
\hline DTI(-6) & $-6375,2(0,000)$ & $-4449,8(0,018)$ & $-2521,6(0,06)$ \\
\hline DTI(-7)+DTI(-8) & $2890,4(0,001)$ & -- & $(--)$ \\
\hline $\operatorname{DLOFCA}(-2)+\operatorname{DLOFCA}(-4)$ & $51,53(0,083)$ & -- & $142,37(0,010)$ \\
\hline $\operatorname{DLOFCA}(-2)+\operatorname{DLOFCA}(-3)$ & -- & $214,51(0,001)$ & $142,37(0,010)$ \\
\hline DLOFCA(-8) & $108,68(0,000)$ & $113,57(0,029)$ & -- \\
\hline $\operatorname{DDDA}(-4)-\operatorname{DPIB}(-4)$ & $11861(0,000)$ & -- & -- \\
\hline DY $(-4)$ & $0,19736(0,004)$ & -- & -- \\
\hline DY $(-7)+$ DY $(-8)$ & $-0,18124(0,014)$ & -- & $0,30663(0,08)$ \\
\hline DRC90(-3)-DCFE(-3) & & -- & $24160(0,000)$ \\
\hline $\operatorname{RESIDY}(-1)$ & $-0,80752(0,000)$ & $-0,44856(0,002)$ & $-0,918(0,000)$ \\
\hline $\mathrm{R}^{2}$ corregido & 0,934 & 0,775 & 0,781 \\
\hline Estadístico de Durbin-Watson & 1,995 & 2,119 & 2,001 \\
\hline
\end{tabular}

Fuente: Elaborado por los autores.

a RESIDY(-1) representa los residuos de la ecuación de cointegración y (FKN, FKNCP o FKNMYLP), con un período de rezago, mientras que DY(-1) es la correspondiente variable explicada en el modelo de corrección de errores, con $i$ rezagos.

asociadas al arbitraje, DREXT(-4), DCFE(-4) y DCFE(-7), es rechazada por los datos, al igual que la exclusión de sólo las variables asociadas al encaje, DCFE(-4) y DCFE(-7). ${ }^{29}$

La estimación de la corrección de errores para los flujos de capital de corto plazo, presentada en la segunda columna del cuadro 5, entrega resultados similares a la de los flujos totales, pero la respuesta de los flujos de corto plazo al encaje es más inmediata y cla-

${ }^{29}$ Con base en una estimación sin restricciones del valor de los parámetros presentada en el apéndice $\mathrm{H}$, cuadro $\mathrm{H} 2$. ramente de mayor fuerza que la de los flujos totales, según es posible comprobar en la simulación del modelo que figura en la sección siguiente. La estimación del modelo de corrección de errores para los flujos de mediano y largo plazo entrega resultados diferentes, los que se hallan en la tercera columna del cuadro 5. Primero, la respuesta de dichos flujos al encaje aparece como reducida; incluso en impacto; el encaje incrementa dichos flujos, muchos de los cuales no eran cubiertos por el gravamen y actuaban como vía de elusión. Con algunos trimestres de rezago la elusión se compensa y el encaje genera algún efecto negativo sobre los flujos de mediano y largo plazo. 


\section{IV}

\section{Simulaciones de políticas para enfrentar capitales externos}

Las ecuaciones para los flujos netos de capital, que figuran en esta sección, en conjunto con las estimaciones para la formación bruta de capital y el resto de la demanda agregada privada que se presentan en el apéndice $\mathrm{C}$, conforman un modelo sobre cuya base es posible evaluar los efectos macroeconómicos del encaje. Las estimaciones para las dos funciones de comportamiento que representan el gasto privado - formación de capital y resto de la demanda interna privadaarrojan resultados convencionales. La única característica saliente de esas estimaciones del gasto privado es que éste responde significativamente a las entradas de capital netas. Los flujos de capital netos totales acumulados anualmente y presentados como porcentaje del producto (FKNAY) fueron incluidos como variable explicativa en las ecuaciones para el gasto privado.

Las simulaciones asociadas a la evaluación de políticas se realizan usando las relaciones de cointegración y las de corrección de errores para representar la dinámica de las variables. La primera pregunta que se intenta responder es si la aplicación del encaje en Chile contribuyó en forma significativa a la estabilización del gasto interno por la vía de atenuar la trayectoria expansiva de los flujos de capital. Una segunda pregunta es si una aplicación más intensa del encaje podría haber evitado por sí sola la sobreexpansión del gasto privado, o si habría sido necesario complementarla con otras políticas.

La primera simulación realizada, modificando variables claves del escenario base, permite calcular los multiplicadores de la respuesta a cambios en variables claves; la segunda calcula los efectos de la eliminación del encaje en 1996, año en que se intensificó la entrada de capital, y la tercera evalúa los ajustes de política que fueron necesarios para reducir la demanda agregada entre $1,5 \%$ y $2 \%$ en 1997, con el fin de limitar la exposición de la economía a una reversión de las corrientes de capital.

\section{Multiplicadores de algunas variables claves}

A continuación se presentan, para la demanda agregada interna y para los flujos netos de capital, las elasticidades de respuesta tras dos años de cambio sosteni- do en la variable de política o la explicativa (cuadro 6). Los resultados confirman la idea expresada antes de que los efectos sobre la demanda agregada y los flujos de capital de los cambios en el CFE son cuantitativamente importantes. El ejercicio se realizó con una variación de 100 puntos base en la tasa de interés real interna, el spread de retornos y el CFE, y una variación de $1 \%$ del PIB en los flujos netos de capital acumulados anualmente (FKNAY) y el gasto de gobierno total. Los resultados muestran las elasticidades de respuesta de los FKNAY y de la demanda agregada interna.

Los cambios en la tasa de interés real afectan el gasto privado de manera directa, por cuanto modifican el costo del financiamiento interno para el consumo y la inversión. Un aumento de 100 puntos base de la tasa de interés real interna reduce la demanda interna en $1,06 \%$ luego de ocho trimestres de aumento sostenido de la tasa. Si el spread de retornos subiese en paralelo con la tasa de interés, el efecto sobre la demanda agregada se moderaría. Un incremento de 100 puntos base del spread corregido de tasas de interés generaría un aumento acumulado anual del flujo neto de capitales de $0,24 \%$ del PIB; por su parte, la entrada de capitales tiene un impacto expansivo sobre el gasto privado, de modo que una ampliación del spread de 100 puntos base se relaciona con un aumento del gasto privado de $0,26 \%$ luego de dos años. Un incremento del encaje puede compensar el efecto expansivo del spread

\begin{tabular}{|c|c|c|}
\hline & \multicolumn{2}{|c|}{$\begin{array}{l}\text { Chile: Respuesta proporcional de los } \\
\text { flujos de capital y demanda interna total en } \\
t+7 \text { a un cambio a partir de } t \text { en la variable } \\
\text { explicativa } \\
\text { (Corrección de errores) }\end{array}$} \\
\hline & $\begin{array}{l}\text { Variación de FKNAY } \\
\text { (en \% del PIB) }\end{array}$ & $\begin{array}{c}\text { Variación de la demanda } \\
\text { interna (en \%) }\end{array}$ \\
\hline$+1 \%$ rc90 & -- & $-1,06$ \\
\hline$+1 \%$ spread & 0,24 & 0,26 \\
\hline$+1 \%$ CFE & $-0,77$ & $-0,67$ \\
\hline$+1 \%$ FKNAY & 1,00 & 0,42 \\
\hline$+1 \%$ LGOB & 0,00 & 0,21 \\
\hline
\end{tabular}

Fuente: Elaborado por los autores. 
sobre los flujos de capital y el gasto privado. El alza del CFE en 100 puntos base - más o menos equivalente a un aumento de 10 puntos porcentuales en la tasa de encaje o de un cuatrimestre en el período de mantención del depósito de encaje- contrae los flujos de capital en $0,77 \%$, y reduce la demanda agregada en $0,67 \%$. Un aumento paralelo del spread y del CFE termina por reducir los flujos de capital y la demanda agregada, de acuerdo con la estimación. Por último, un incremento del gasto de gobierno de $1 \%$, si bien no afecta los flujos de capital, sí eleva la demanda agregada en $0,21 \%$.

\section{Escenario de eliminación del encaje}

Para identificar cuáles habrían sido los resultados macroeconómicos si el encaje no se hubiese aplicado, presentamos a continuación un ejercicio de simulación, utilizando los resultados de la estimación que figura en la sección anterior. El ejercicio intenta una aproximación a cuál habría sido el comportamiento de los flujos netos de capital, de la formación bruta de capital y del resto de la demanda interna si se hubiese dejado de aplicar la política de encaje a las entradas de capital; es decir, si el CFE se hubiese llevado a cero a partir del primer trimestre de 1995. De haber sido nula la efectividad del encaje, llevar el CFE a cero no habría alterado el valor del resto de las variables macroeconómicas, en particular los flujos de capital y la demanda interna. Como se muestra en el gráfico 2, la simulación realizada sobre la base de las estimaciones que se presentaron en la sección anterior no indican que la eficacia del encaje fue nula ni tampoco que su efecto sobre los flujos de capital totales y la demanda agregada haya sido irrelevante.

Sin encaje, la demanda interna se habría expandido aún más fuertemente en 1996 y 1997, llegando durante el último de estos años a exceder el nivel del escenario base en 1,6\% del PIB. Como se aprecia en el gráfico 3, la eliminación del encaje en 1995 habría llevado a amplificar el ciclo. En efecto, a contar del tercer trimestre de 1996 y hasta el tercer trimestre de 1998, la demanda interna como porcentaje del PIB fue entre uno y dos puntos porcentuales mayor que la del escenario base. Siendo todo lo demás constante, este gasto adicional habría hecho que el déficit en la cuenta corriente en 1997 fuera de alrededor de 7\%, en vez de girar en torno al 5\% del PIB como lo hizo efectivamente ese año, implicando una mayor vulnerabilidad de la economía a un empeoramiento de la situación externa.
GRAFICO 2

Chile: Simulación de eliminación del encaje, 1995 a 1997

(Flujo neto de capitales acumulado anualmente - FKNAY -, en porcentaje del PIB)

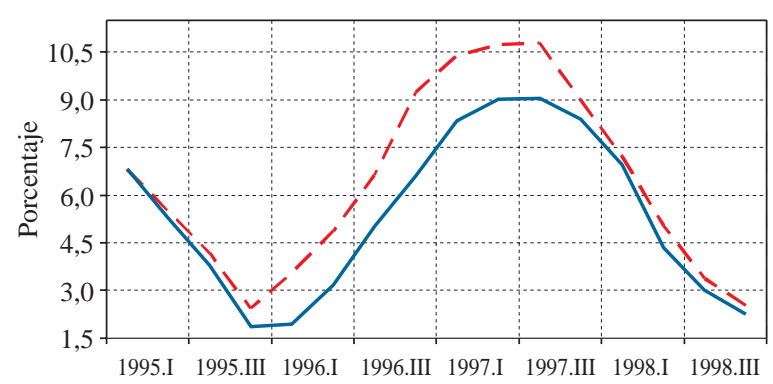

FKNAY

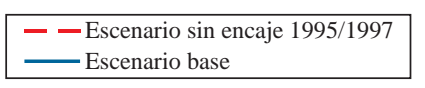

Fuente: Elaborado por los autores.

GRAFICO 3

Chile: Simulación de eliminación del encaje, 1995 a 1997

Demanda agregada

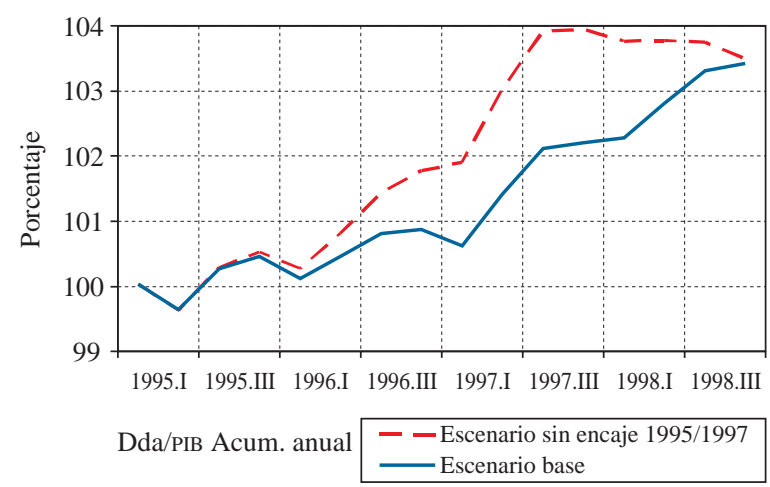

Fuente: Elaborado por los autores.

Es posible concluir que si bien el encaje no evitó la sobreexpansión del gasto privado de 1996 y 1997, su efecto no dejó de ser relevante, pues de no haberse aplicado el exceso de gasto habría sido notablemente más grave, o habría habido necesidad de otras compensaciones, como una política fiscal mucho más contractiva, simplemente para mantenerse en el mismo nivel de gasto agregado.

En el gráfico 4 se muestran las desviaciones de los flujos de capital netos totales y de corto plazo en un escenario de eliminación de encaje respecto del escenario base. Queda claro en la simulación que la desviación de los flujos de corto plazo más que doblaría la de los flujos totales; así, la ampliación de los flujos de corto plazo por la eliminación del encaje llega 
GRAFICO 4

Chile: Simulación de eliminación del encaje, 1995 a 1997

Desviaciones del flujo de capitales respecto del escenario base

(Desviación acumulada anual, en \% del PIB)

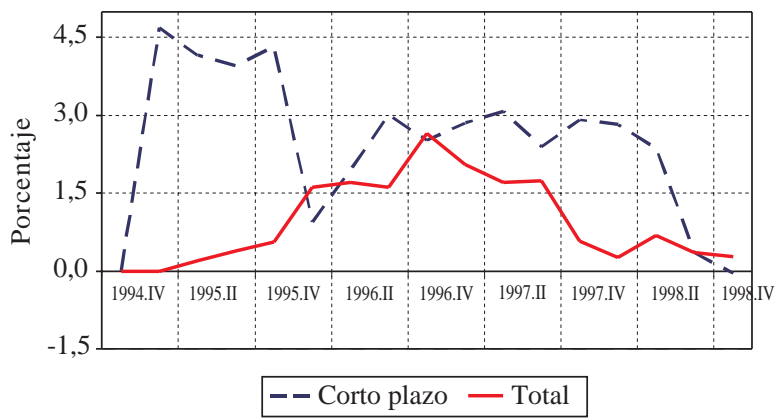

Fuente: Elaborado por los autores.

hasta 4,5\% del PIB, mientras que la de los flujos totales es de 1,5\% del PIB. Tal diferencia debería ser compensada por una caída de los flujos de mediano y largo plazo en respuesta a la eliminación del encaje. Esto demuestra el fuerte efecto del encaje sobre los flujos de corto plazo y, en consecuencia, su efectividad para modificar la composición del financiamiento externo para favorecer flujos de mediano y largo plazo.

Desde luego, es posible concebir una combinación de políticas distintas a la efectivamente aplicada si el encaje hubiese sido eliminado, pero ello habría significado superar otros problemas. Si junto con eliminar el encaje se hubiese reducido la tasa de interés en un monto equivalente a la reducción del CFE, se habría generado una expansión de la demanda agregada como resultado de las menores tasas de interés. Es posible que la menor tasa de interés hubiese resultado en una caída en el spread de retornos que habría evitado en parte la mayor entrada de capital relacionada con el menor CFE. Pero para esto es necesario suponer que la baja de la tasa de interés no habría afectado al tipo de cambio, de manera que el spread de retornos esperados hubiese compensado la reducción del CFE.

\section{Escenarios de ajuste macroeconómico}

Un segundo ejercicio de simulación es el de aplicar los resultados de la estimación para definir acciones de política que hubiesen permitido moderar la expansión del gasto en 1996 y 1997. Una reducción del nivel del gasto agregado equivalente a 1,5\% del PIB en 1997 habría bastado para reducir el déficit en cuenta corriente a un valor en torno a 4\% del PIB. Posibles acciones con este fin incluyen alzas en la tasa de encaje y en la tasas de interés. En 1996 y 1997 el tipo de cambio se mantuvo cerca del piso de la banda, de modo que existía una rigidez para que el tipo de cambio se apreciara como respuesta a una acción de política monetaria contractiva. En consecuencia, un aumento de la tasa de interés con rigidez cambiaria debería haber significado una ampliación del spread esperado, lo que habría estimulado la entrada de capitales adicionales. Sin embargo, como no contamos con una relación que explique el comportamiento del spread para los fines del ejercicio de simulación, sólo se variará la tasa de encaje, dejando inalterados el spread y la tasa de interés interna.

Un aumento de 150 puntos base del costo financiero del encaje - logrado, por ejemplo, llevando el plazo de vigencia del depósito de encaje de 12 a 18 meses - habría reducido los flujos totales de capital (FKNAY) $^{30}$ en 1,2\% del PIB en 1996 y en 0,4\% del PIB en 1997 (gráfico 5). Al reducirse los flujos netos de capital en respuesta al mayor costo del encaje, el gasto agregado habría disminuido, pero sólo en $0,2 \%$ del PIB en 1996 y, en forma algo más significativa, en $0,75 \%$ del PIB al año siguiente. Sin embargo, un aumento de 150 puntos base en el CFE no habría sido suficiente para generar el ajuste buscado para la demanda global, y considerar incrementos todavía mayores plantea problemas de eficacia. La existencia de flujos de capital no cubiertos por el encaje resulta en un comportamiento particular de las corrientes de mediano y largo plazo, las que casi no se reducen ante alzas del CFE, y, más aún, cuyo impacto tiende a aumentar. Por lo tanto, una vez que los flujos de corto plazo convergen a cero como resultado del alza en el costo financiero del encaje, se agota la efectividad marginal del instrumento para controlar los flujos netos totales y, por ende, el gasto privado. Esto porque sólo es razonable suponer que el encaje frena la entrada de capital, pero no que genera salidas netas de capitales de corto plazo.

Como muestra el gráfico 6, en el escenario con aumento de 150 puntos base en el CFE la entrada neta anual de capitales de corto plazo habría llegado a ser inferior a cero en gran parte del período 1995-1997. Esto indica el agotamiento del mecanismo de encaje para influir adicionalmente sobre los flujos totales y el gasto privado. ${ }^{31}$

\footnotetext{
${ }^{30}$ Acumulados anualmente, de manera que el valor que se considera representativo de cada año en el gráfico corresponde al último trimestre del año respectivo.

31 Argumento análogo al que se da en el comercio internacional según el cual, por alto que sea el nivel del arancel a las importaciones, éste nunca permitirá que un sustituto de importación se convierta en bien exportable.
} 
GRAFICO 5

Chile: Simulación de escenario de ajuste para los flujos de capitales Incremento del costo financiero del encaje en 150 puntos base, 1995-1997

(Flujo neto de capitales acumulado anualmente, en $\%$ del PIB)

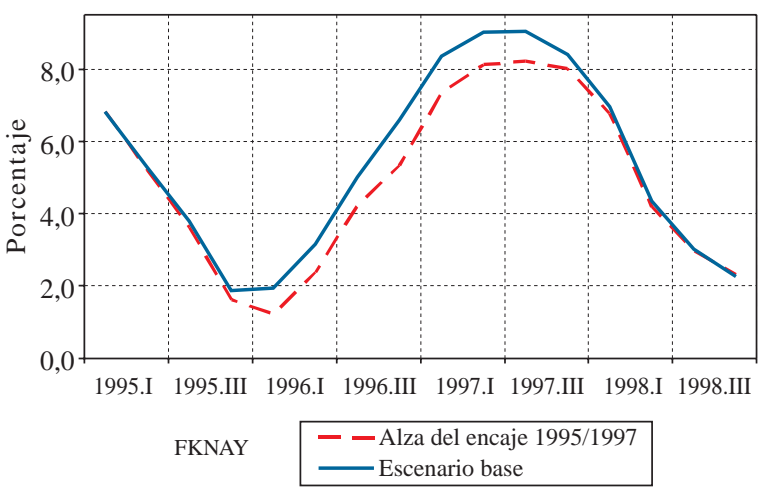

Fuente: Elaborado por los autores.

La efectividad marginal del encaje estaba muy acotada en la medida en que su aplicación siguiera siendo selectiva. Para evitar la elusión del encaje, que limitó su eficacia, habría sido necesario eliminar las excepciones a él existentes en el endeudamiento comercial directo con proveedores externos o con compradores de exportaciones, y en algunas formas de inversión de cartera; sin embargo, esa medida despertaba fuertes resistencias en el sector privado y casi ningún apoyo en el sector público. Lo interesante es que una extensión del encaje a flujos de capital no cubiertos no sólo habría incrementado su efectividad macroeconómica, sino que además habría reducido los costos microeconómicos en gran parte asociados a las diferencias en el costo del financiamiento para quienes podían o no podían eludir el encaje. ${ }^{32}$ Lamentablemente, no nos es posible simular cuál habría sido la respuesta de los flujos de capital a una aplicación ampliada del encaje. No es adecuado suponer que su generalización habría hecho que los flujos de mediano y largo plazo se comportaran como los de corto plazo. Por diseño, el CFE que habría afectado a los flujos de mediano y largo plazo que pasarían a ser cubiertos por el encaje habría sido muy inferior al que había afectado a los flujos de corto plazo.

\footnotetext{
32 Incluso la inversión directa se utilizó como vía de elusión del encaje, al disfrazarse de tal flujos que en realidad constituían inversión financiera o de cartera. En Le Fort y Sanhueza (1997) se examinan las vías de elusión y se defiende una generalización de mecanismo.
}

GRAFICO 6
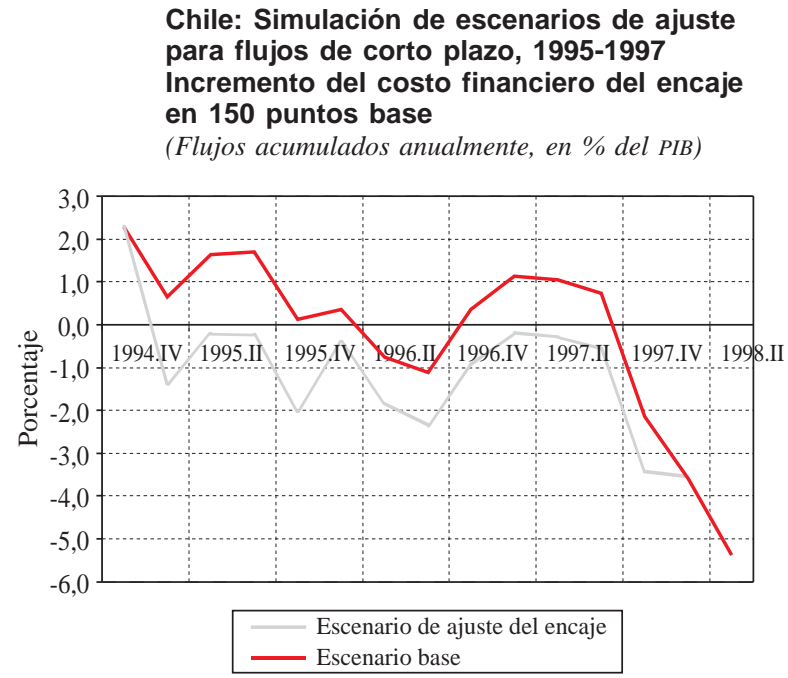

Fuente: Elaborado por los autores.

Para complementar el efecto de la posible alza del CFE sobre la demanda agregada, lo más adecuado habría sido considerar el uso de una política fiscal contracíclica. Esta política acepta un balance fiscal más elevado, incluso superavitario, en los períodos de rápida expansión de la actividad y el gasto, y un balance más bajo, incluso deficitario, en los períodos de menor actividad. De esta forma la expansión del gasto público se daría en línea con el crecimiento tendencial de los ingresos públicos y no siguiendo sus altibajos cíclicos. ${ }^{33}$ Para los efectos de la simulación de una política fiscal contracíclica planteamos un escenario con una expansión del gasto de gobierno de 5\% real por año en 1996-1997, en lugar del 7\% de expansión media efectiva del gasto en esos dos años. Complementando con ese ajuste fiscal el del costo financiero del encaje, se habría podido obtener una reducción de la demanda agregada respecto del escenario base de 1,0\% del PIB en 1996 y de 1,8\% del PIB en 1997 (gráfico 7). En virtud de este ajuste global — de encaje y fiscal- el déficit de la cuenta corriente podría haber estado bajo 4\% del PIB en 1997, reduciendo así los efectos potenciales de una reversión de los flujos de capital.

Es necesario mencionar que existía otro curso de acción para moderar las entradas de capitales, pero al contrario de los casos anteriores requería aceptar una

\footnotetext{
${ }^{33}$ Véase el análisis de una política fiscal contracíclica en Budnevich y Le Fort (1997).
} 
GRAFICO 7

Chile: Simulación de escenarios de ajuste. Incremento del costo financiero del encaje y menor crecimiento del gasto del gobierno, 1996, 1997 y 1998

(Desviaciones de la demanda interna, en \% del PIB)

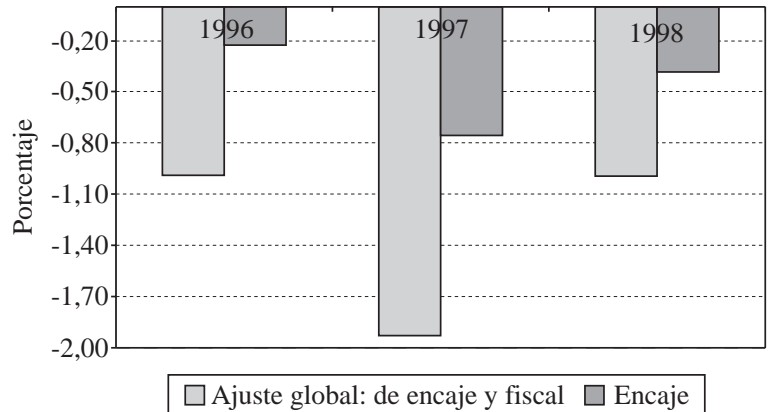

Fuente: Elaborado por los autores.

mayor apreciación real de la moneda. Permitiendo una mayor apreciación real del peso se habría reducido el spread corregido de tasas de interés en virtud de un incremento de la devaluación esperada, y con ello

\section{V}

\section{Conclusiones}

Del análisis del episodio de fuertes entradas de capital a Chile podemos obtener un conjunto de enseñanzas sobre el comportamiento de los flujos de capital y de su relación con políticas y variables macroeconómicas.

En primer lugar, Chile sufrió los efectos de una masiva entrada de capitales de 1990 a 1997, y de su posterior reversión a partir de 1998. La intensificación de la afluencia de capital fue particularmente marcada en 1996 y 1997 y estuvo concentrada en corrientes de mediano y largo plazo. Estas son menos volátiles y más persistentes que las de corto plazo, lo que hace más deseable un financiamiento externo concentrado en ellas. Pero la concentración del financiamiento externo en flujos de mediano y largo plazo probó no ser protección suficiente, ya que no evitó que estos se revirtieran. Lo expuesto subraya la importancia de usar el total del financiamiento externo como elemento determinante de la probabilidad de reversión de las entradas de capital.

En segundo lugar, la intensificación de los flujos de capital de mediano y largo plazo tuvo las caracte- habrían disminuido la entrada de capitales y el gasto privado. Cabe reconocer, sin embargo, que este curso de acción implica riesgos difíciles de anticipar. Es posible que la apreciación real no hubiese generado en forma inmediata expectativas de depreciación, como se ha supuesto en este modelo, sino que, por el contrario, la mayor apreciación hubiese originado, al menos transitoriamente, expectativas de nuevas apreciaciones; esto desembocaría en una profunda desalineación del tipo de cambio con efectos serios sobre la asignación de recursos y la estabilidad macroeconómica. Más allá del efecto expansivo o contractivo de la variable que origina la apreciación real, existe alguna evidencia empírica de que tal apreciación está asociada a una expansión del gasto privado. Por una parte, porque el sector privado chileno tiene pasivos netos en moneda extranjera (la deuda externa chilena es predominantemente privada), cuyo valor real cae con la apreciación real, y por otra, porque gran parte de la masa de consumidores son asalariados cuyo ingreso real es en esencia un bien no transable cuyo precio relativo sube con la apreciación real. ${ }^{34}$ rísticas de una perturbación exógena de oferta más que de una respuesta endógena de arbitraje a tasas de interés internas elevadas. Esa intensificación se asocia en particular con una baja de la tasa de interés interna y, por lo tanto, con un incremento estructural en la oferta de capitales externos.

En tercer lugar, la atracción de financiamiento externo por arbitraje de rentabilidades, dadas tasas de interés internas superiores a las externas, se observó sólo para los flujos de corto plazo y de manera parcial. Hay indicaciones de que el encaje ayudó a compensar este efecto, dando margen adicional para la operación de la política monetaria. De hecho, el spread

\footnotetext{
34 También es posible que la apreciación real genere una redistribución del ingreso hacia grupos con una mayor propensión marginal al consumo, resultando por ende en un mayor gasto privado. La apreciación real haría subir los salarios reales y reduciría las utilidades. Si la propensión marginal a consumir de los trabajadores es mayor que la de quienes reciben la renta del capital, entonces la apreciación real es expansiva del consumo.
} 
efectivo de retornos entre activos internos y externos muestra una cierta respuesta positiva a las alzas del CFE, y negativa a los incrementos de la oferta de capitales. En el mismo sentido, la tasa de interés real interna, y hasta cierto punto el tipo de cambio real, también reaccionan ante aumentos del CFE.

En cuarto lugar, el encaje fue eficaz para reducir los flujos de capitales totales y modificar su composición en favor de los de mediano y largo plazo. Tanto las estimaciones de cointegración como las de corrección de errores muestran respuestas estadísticamente significativas de los flujos de capital al CFE, particularmente mientras se considere la oferta de capitales como determinante de los flujos de capitales. La eliminación del encaje durante el período de intensificación de las entradas de capital habría producido efectos macroeconómicos no despreciables, entre ellos un incremento de los flujos de capital netos estimado en torno a $2 \%$ del PIB y un serio empeoramiento de la sobreexpansión del gasto que ya estaba sufriendo la economía chilena a mediados de la década de 1990 , con un incremento de la demanda interna del orden de 1,5\% del PIB en 1997.

En quinto lugar, la efectividad marginal del encaje tal como estaba diseñado era limitada, porque existía poco espacio para que un aumento de su costo financiero siguiera reduciendo las entradas de capitales de corto plazo sobre los cuales actuaba de preferencia. En cambio, la mayor elusión del encaje por la vía de los flujos de mediano y largo plazo no tenía límites, a menos que se modificaran las regulaciones con miras a ampliar la aplicación de la medida y evitar vías de elusión. Una estrategia más eficaz para controlar la afluencia de capitales y la demanda interna habría exigido un refuerzo adicional del encaje, no sólo elevando su costo financiero, sino además ampliando su aplicación y apoyándolo con una política fiscal contracíclica.

En sexto lugar, la efectividad del encaje sobre los flujos de capital netos (FKN) se origina en la compensación que el encaje permite ante la intensificación de las entradas de capital por aumento de la oferta de capital externo. Si esa intensificación derivada de las condiciones de la oferta de capital no es reconocida y las variables de oferta de capital se excluyen de la especificación de la ecuación para los flujos de capital netos, entonces el encaje no tiene un efecto estadísticamente significativo en los flujos. Como además la capacidad del modelo para explicar los flujos de capital se deteriora notablemente, la exclusión del encaje y las variables de oferta de capital es rechazada por los datos.

Por último, el efecto de la política monetaria sobre el gasto interno puede verse debilitado por las entradas de capital. Este debilitamiento se da si el tipo de cambio no puede fluctuar libremente en respuesta a los cambios en la tasa de interés. Si la moneda no puede apreciarse para compensar los posibles efectos de las alzas de la tasa de interés interna sobre el spread de tasas, las entradas de capitales adicionales debilitan el efecto de la política monetaria contractiva sobre el gasto interno y complican el esfuerzo de estabilización del tipo de cambio. La flotación cambiaria devuelve la efectividad a la política monetaria; sin embargo, ante una intensificación de las entradas de capital como la de 1996-1997, dejar que la moneda flote puede implicar un riesgo nada despreciable de sobreapreciación cambiaria, con efectos potencialmente muy nocivos sobre la asignación de recursos y la estabilidad externa.
Agosin, M. y R. Ffrench-Davis (2001): Managing capital inflows in Chile, en S. Griffith-Jones, M.F. Montes y A. Nasution (comps.), Short-Term Capital Flows and Economic Crises, Nueva York, Oxford University Press.

Bhagwati, J. (2003): Testimony, Committee on Domestic and International Monetary Policy, Trade and Technology, Washington, D.C., U.S. House of Representatives Committee on Financial Services, abril.

Budnevich, C. y G. Le Fort (1997): La política fiscal y el ciclo económico en Chile, Revista de la CEPAL, Nº 61, LC/G.1955-P, Santiago de Chile, abril.

Caballero, R. (2003): On the International Financial Architecture: Insuring Emerging Markets, documento presentado al Seminario de la Junta Ejecutiva del FMI, Washington, D.C., 27 de mayo.
Calvo, G. y C. Reinhardt (2000): When capital inflows suddenly stop: consequences and policy options, en P. Kenen y A. Swoboda (comps.), Reforming the International Monetary and Financial System, Washington, D.C., Fondo Monetario Internacional (FMI)

Chumacero, R., R. Labán y F. Larraín (2000): What determines capital inflows? An empirical analysis for Chile, en F. Larraín (comp.), Capital Flows, Capital Controls and Currency Crises, Ann Arbor, The University of Michigan Press.

De Gregorio, J., S. Edwards y R. Valdés (2000): Controls on Capital Inflows: Do They Work?, NBER Working Paper, № 7645, Cambridge, Massachusetts, National Bureau of Economic Research.

Enders, W. (1995): Applied Econometric Time Series, Nueva York, John Wiley and Sons. 
FMI (Fondo Monetario Internacional) (varios años): Perspectivas de la economía mundial, Washington, D.C.

Forbes, K. (2003): One Cost of the Chilean Capital Controls, Increasing Financial Constraints for Small Trade Firms, NBER Working Paper, $N^{\circ}$ 9779, Cambridge, Massachusetts, National Bureau of Economic Research, junio.

Gallego, F., L. Hernández y K. Schmidt-Hebbel (2002): Capital controls in Chile: were they effective?, en L. Hernández y K. Schmidt-Hebbetl (comps.), Banking Financial Integration, and International Crises, tomo 3, Santiago de Chile, Banco Central de Chile.

Guajardo, J. y G. Le Fort (1999): Cuenta corriente y desvíos transitorios en términos de intercambio y volúmenes de exportaciones: Chile 1985-1999, Documentos de trabajo, $\mathrm{N}^{\circ} 49$, Santiago de Chile, Banco Central de Chile, noviembre.

Gulde-Wolf, A., D. Hoelsher y otros (2003): Financial Stability in Dollarized Economies, IMF Occasional Papers, Washington, D.C., Fondo Monetario Internacional, por aparecer.

Kose, A., E. Prasad y otros (2003): Effects of Financial Globalization on Developing Countries-Some Empirical Evidence, IMF Occasional Papers, Washington, D.C., Fondo Monetario Internacional, por aparecer.

Kruger, M. (1998): Capital flows and exchange rates: a Canadian perspective, Banco de México, Conferencia de Bancos Centrales de la Cuenca del Pacífico, noviembre.

Laurens, B. y J. Cardoso (1998): Managing Capital Flows: Lessons from the Experience of Chile, IMF Working Paper, $\mathrm{N}^{\mathrm{o}} 168$, Washington, D.C., Fondo Monetario Internacional (FMI).

Leamer, E. (1983): Let's take the con out of econometrics, American Economic Review, $\mathrm{N}^{\circ}$ 1, vol. 73, Nashville, Tennessee, American Economic Association.

Lehmann, S. (1998): Investment under Uncertainty and Financial Market Development, Documento de trabajo, No 17, Santiago de Chile, Banco Central de Chile.

Le Fort, G. (1998): La política monetaria, el tipo de cambio real y el encaje al influjo de capitales: un modelo analítico simple,
Documento de trabajo, № 36, Santiago de Chile, Banco Central de Chile.

Le Fort, G. y S. Lehmann (2000): El encaje, los flujos de capitales y el gasto: una evaluación empírica, Documento de trabajo, $\mathrm{N}^{\circ}$ 64, Santiago de Chile, Banco Central de Chile.

Le Fort, G. y G. Sanhueza (1997): "Flujo de capitales y encaje en la experiencia chilena de los 90", Santiago de Chile, Banco Central de Chile, inédito.

Massad, C. (1998): The liberalization of the capital account: Chile in the 1990s, Princeton Essays in International Finance, N $^{\circ} 207$, Princeton, Princeton University Press, mayo.

Milessi Ferreti, G. y A. Razin (1996): Current account sustainability, Princeton Studies in International Finance, $N^{\circ}$ 81, Princeton, Princeton University Press, octubre.

Nadal-De Simone, F. y P. Sorsa (1999): A Review of Capital Account Restrictions in Chile in the 1990s, IMF Working Paper, $\mathrm{N}^{\circ} 52$, Washington, D.C., Fondo Monetario Internacional (FMI).

Soto, C. (1997): Controles a los movimientos de capitales: evidencia empírica del caso chileno, tesis para optar al grado de magíster en economía, Santiago de Chile, Facultad de Ciencias Económicas y Administrativas, Universidad de Chile, abril.

Soto, C. y R. Valdés (1998): Desalineamiento del tipo de cambio real en Chile, Santiago de Chile, Banco Central de Chile, inédito.

The Economist (2003a): A cruel sea of finance, Londres, 1 de mayo. (2003b): A place for capital controls, Londres, 1 de mayo

Valdés, S. y M. Soto (1996): ¿Es el control selectivo de capitales efectivo en Chile? Su efecto sobre el tipo de cambio real, Cuaderno de economía, $\mathrm{N}^{\circ}$ 33, Santiago de Chile, Pontificia Universidad Católica de Chile.

Zahler, R. (1996): Exposición del Presidente del Banco Central de Chile en la Conferencia Inaugural del Seminario " $70^{\circ}$ Aniversario del Banco Central de Chile", Estudios monetarios XII, Santiago de Chile, Banco Central de Chile, junio. 
APENDICE A

\section{Glosas de variables}

Diferencial de retornos esperados entre activos internos y externos (spread)

Esta variable representa la diferencia entre el retorno esperado de activos en pesos y de activos en dólares. Se calcula de acuerdo con la siguiente ecuación:

$$
\text { Spread }=r\left(i^{*}-\pi^{*}+s\right)-E \hat{T} C R
$$

donde,

$r \quad$ : Tasa de colocación real de 90-365 días

$i^{*} \quad$ : Libor en dólares.

$\pi^{*} \quad$ : Índice de precios al por mayor de Estados Unidos

s : Riesgo país o margen del soberano

$\hat{E} T C R$ : Devaluación esperada, calculada como la desviación del tipo de cambio efectivo con respecto al tipo de cambio de equilibrio, según Soto y Valdés (1998).

Diferencial efectivo de retornos entre activos internos y externos (spread_2)

Igual a la variable anterior, sólo que la diferencia corresponde al retorno efectivo de activos en pesos y de activos en dólares. Se calcula usando la variación forward efectiva del tipo de cambio real.

$$
\text { Spread_2 }=r-\left(i^{*}-\pi^{*}+s\right)-\hat{T C R}
$$

$T \hat{C} R$ : Devaluación real efectiva forward, o esperada bajo perfecto conocimiento del futuro.

\section{Costo financiero del encaje (CFE)} riable:

La siguiente ecuación establece el cálculo de esta va-

$$
C F E=\frac{\varepsilon}{1-\varepsilon} \frac{i^{*}+s}{1-t}
$$

donde:

$\varepsilon \quad: \quad$ Tasa de encaje del período

$i^{*} \quad$ : Tasa Libo a un año.

$s \quad$ : Spread promedio de los créditos externos financieros de corto plazo

$t$ : Impuesto asociado al retorno de las instituciones financieras: $4 \%$.

Dado que desde la imposición del encaje a los flujos de capitales hasta diciembre de 1994 era permitido constituir el encaje en la moneda de origen de la operación, para ese período se consideró el CFE mínimo entre los resultantes de considerar la Libor en dólares, en marcos alemanes y en yenes. Las regulaciones vigentes desde enero de 1995 obligan a constituir el encaje en dólares; por lo tanto, a partir de ese año se utilizó el cfe construido con la Libor en dólares (Fuente: Le Fort y Sanhueza, 1996).
Tasa de interés interna de colocación (rc90)

Tasa de interés promedio del sistema bancario para préstamos en unidades de fomento (UF), 90-365 días. Fuente: Banco Central.

Tasa de interés externa nominal (libo90=i*)

Libor en dólares a 90 días. Fuente: Banco Central

Tasa de interés externa real (rext): rext $=i^{*}-\pi^{*}+s$

Tipo de cambio real, en log (LTCR)

Fuente: Banco Central.

Variable ficticia (dummy) de reversión de flujo de capitales (DUM98)

Valor 0 hasta el último trimestre de 1997 y 1 a partir del primero de 1998.

Índice de oferta de flujos de capitales externos, en log (LOFCA)

Se construye ponderando los flujos destinados a Argentina, Brasil, México (según cuenta de capitales, IFS) por el respectivo spread de su deuda, dividido por el spread de los bonos chilenos. Elaboración propia con base en datos de J.P. Morgan.

Flujo neto de capitales de corto plazo (FKNCP) incluyendo errores y omisiones, líneas de crédito, préstamos de corto plazo y variación de activos externos; Flujo neto de capitales de mediano y largo plazo (FKNMYLP), incluyendo inversión directa y de cartera y créditos de mediano y largo plazo; y Flujo neto de capitales (FKN+FKNCP). Fuente: Banco Central.

Flujo neto de capitales acumulado anual en porcentaje del PIB (FKNAY)

Fuente: Elaboración propia usando datos de FKN acumulados anualmente y expresado como porcentaje del PIB.

Gap del producto (Gaphpy)

Fuente: Variable construida aplicándole al PIB real trimestral acumulado de los últimos cuatro trimestres y expresado en logaritmos el filtro Hodrick-Prescott. El gap se define como el PIB filtrado menos el PIB efectivo.

Profundidad del sistema financiero en log (LFIN)

Tendencia de patrimonio bursátil de Chile como porcentaje del PIB.

Fuente: Lehmann (1998).

Índice de Riesgo Euromoney de Chile (IRE)

Índice construido por Euromoney, rango 0-100. Se ponderan factores económicos y sociopolíticos, determinan- 
do la clasificación de riesgo-país para cada economía. Mientras más alto es este índice, mejor es la clasificación de riesgo del país. Fuente: Euromoney.

Producto interno bruto, en log (LPIB)

Fuente: Banco Central.

Demanda agregada interna, en log (LDDA)

Fuente: Banco Central.

Formación bruta de capital fijo, en log (LFBKF)

Fuente: Banco Central.

Resto de la demanda agregada interna, en log (LRESTD) Fuente: Banco Central.

Índice de términos de intercambio, en log (LTI)

Fuente: Banco Central de Chile.

Gasto de gobierno, en log ( $L G O B)$

Fuente: Ministerio de Hacienda
Gasto de gobierno en formación de capital (GOBFBK)

Fuente: Ministerio de Hacienda

Gasto de gobierno resto (GOBRST)

Fuente: Ministerio de Hacienda

Formación bruta de capital fijo privada, en log (LFBKPR)

FBKPR $=$ FBKF - GOBFBK

Resto de la demanda agregada interna privada, en log (LRSTPR)

RSTPR $=$ RESTD - GOBRST

Recaudación tributaria, en log (LTRIB)

Fuente: Ministerio de Hacienda

Crecimiento PIB Mundial $\left(g_{\text {Mundo }}\right)$ y Crecimiento PIB Estados Unidos $\left(g_{U S A}\right)$

Fuente: Bloomberg 
APENDICE B

\section{Gráficos de principales variables}

Gráfico B1: Spread

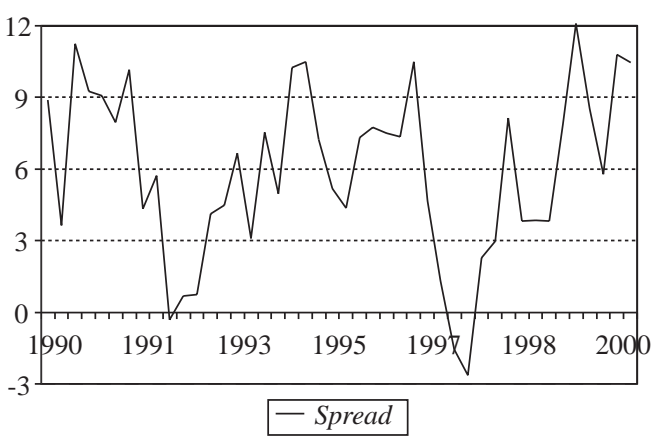

Gráfico B3: Costo financiero del encaje

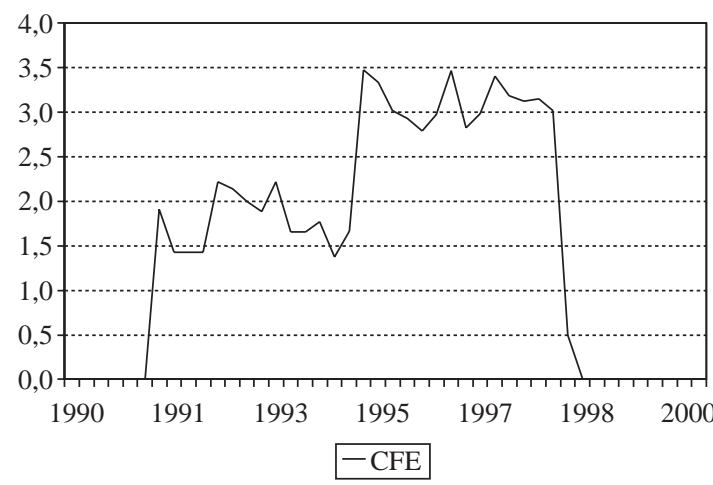

Gráfico B5: Libo90

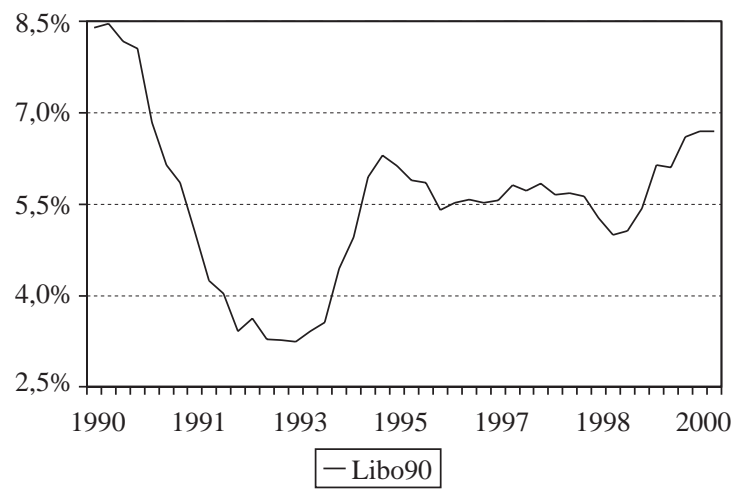

Gráfico B2: Spread_2

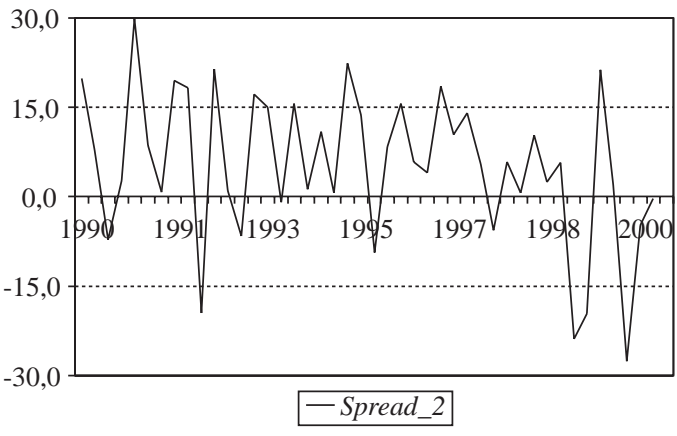

Gráfico B4: rc90

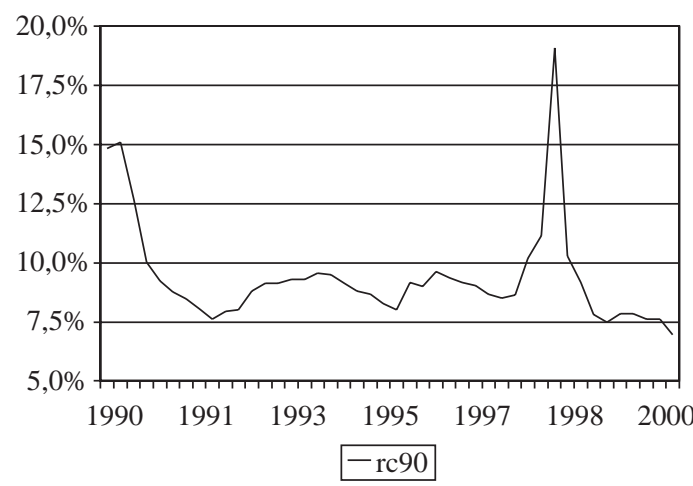

Gráfico B6: REXT

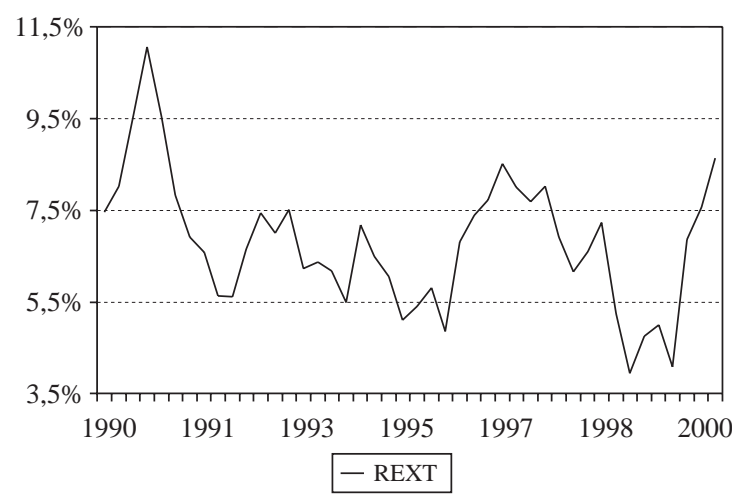


Gráfico B7: LTCR

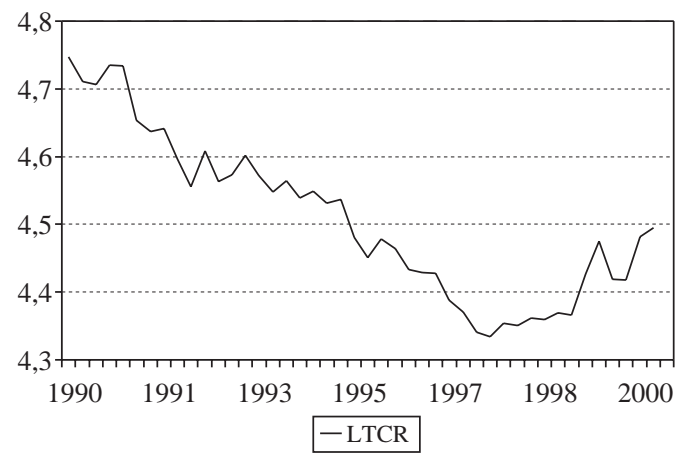

Gráfico B9: LOFCA

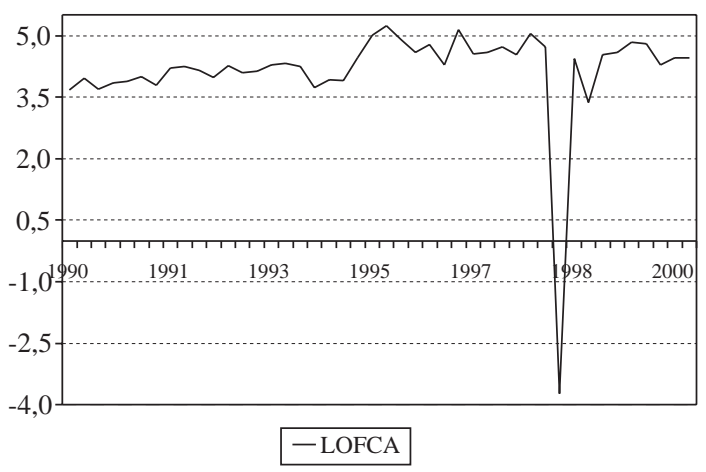

Gráfico B11: FKNCP

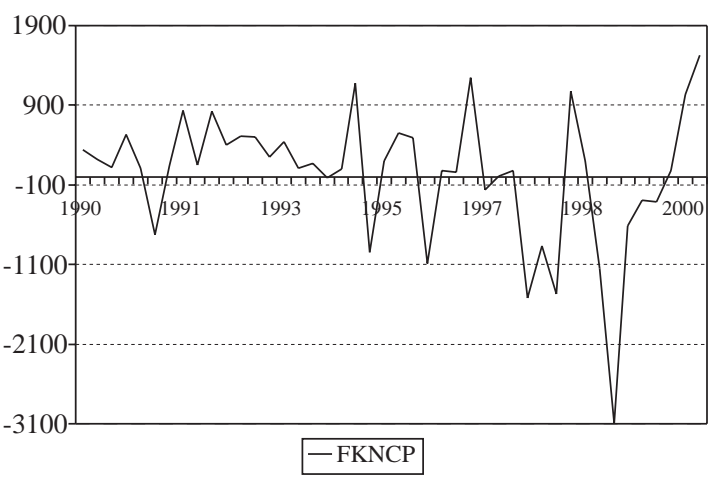

Gráfico B8: Dum98

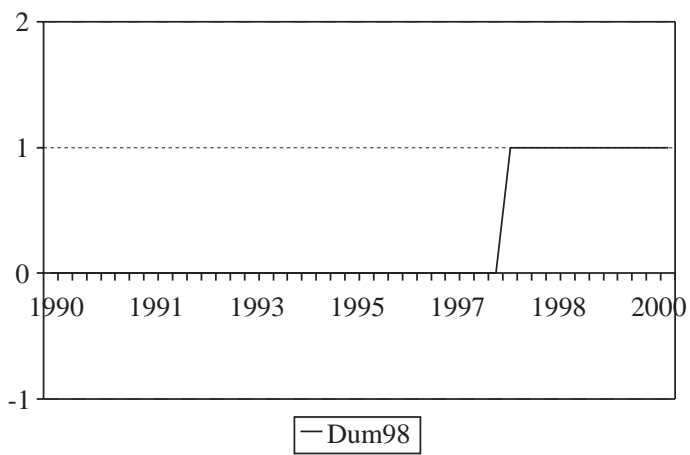

Gráfico B10: FKN

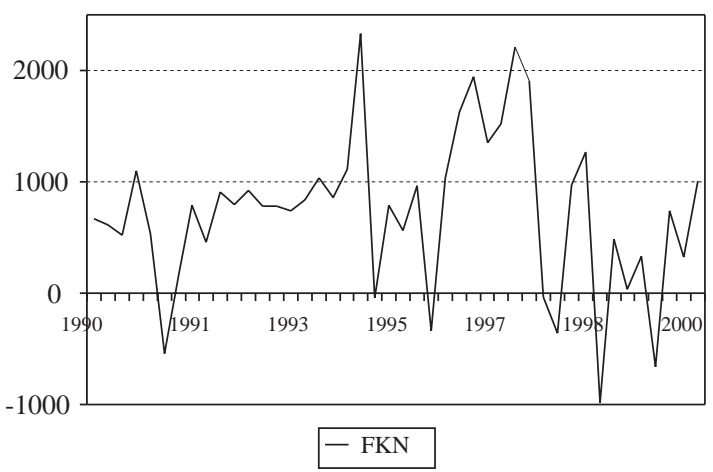

Gráfico B12: FKNMYLP

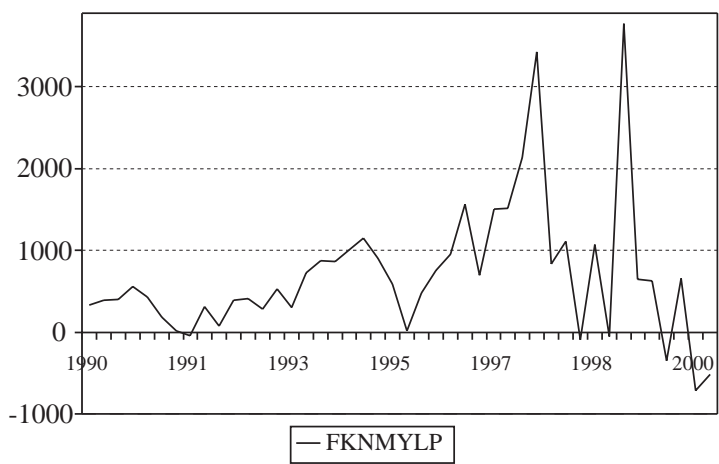


Gráfico B13: FKNAY

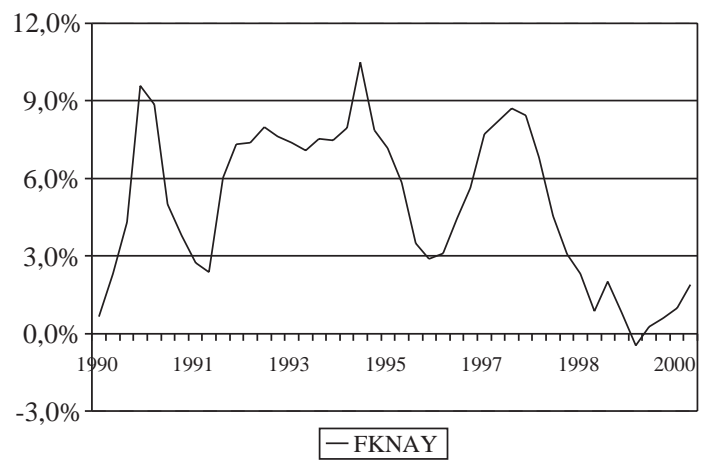

Gráfico B15: LDDA

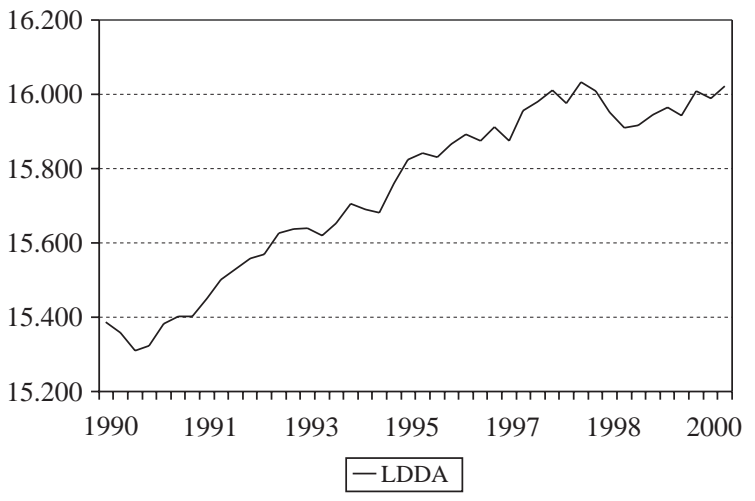

Gráfico B17: GAPHPY

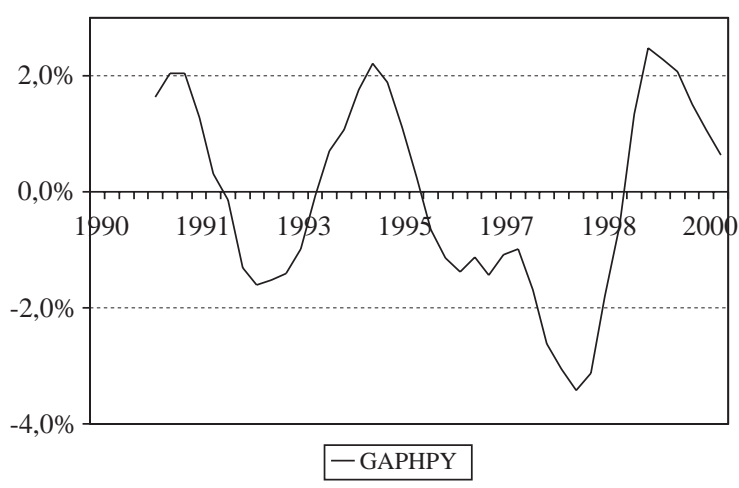

Gráfico B14: LFBKF

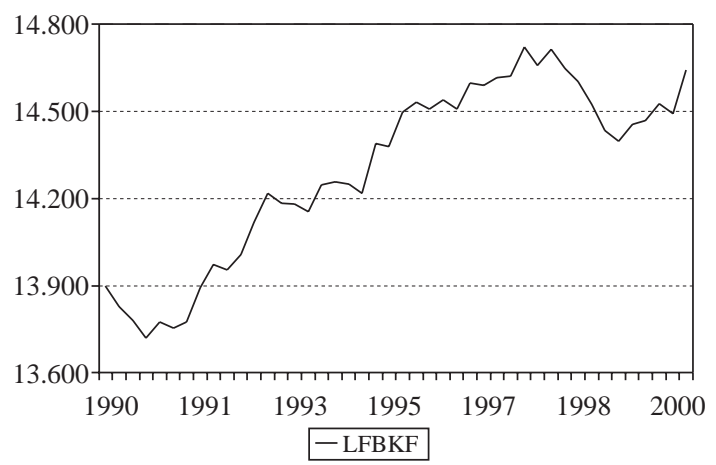

Gráfico B16: LPIB

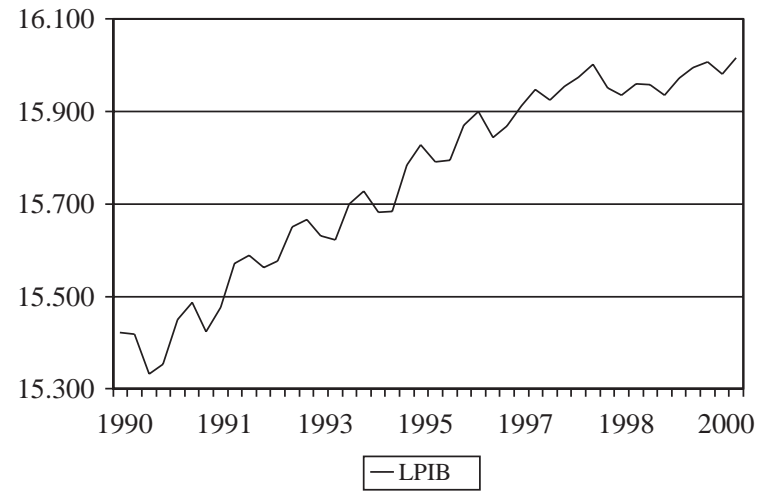

Gráfico B18: LFIN

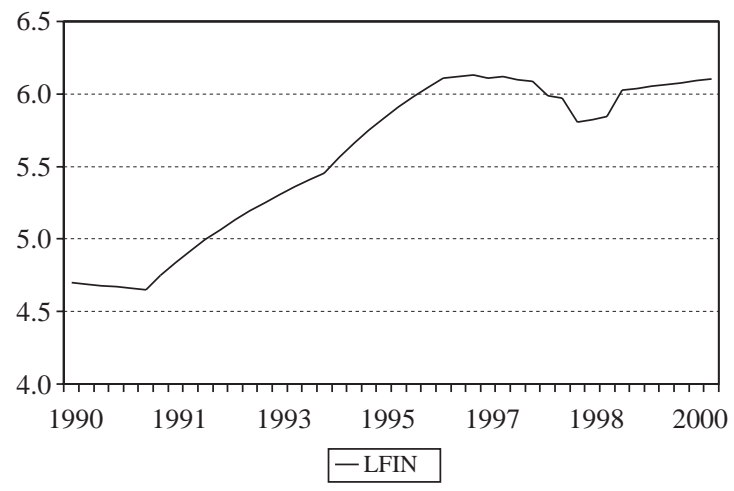


Gráfico B19: LGOB

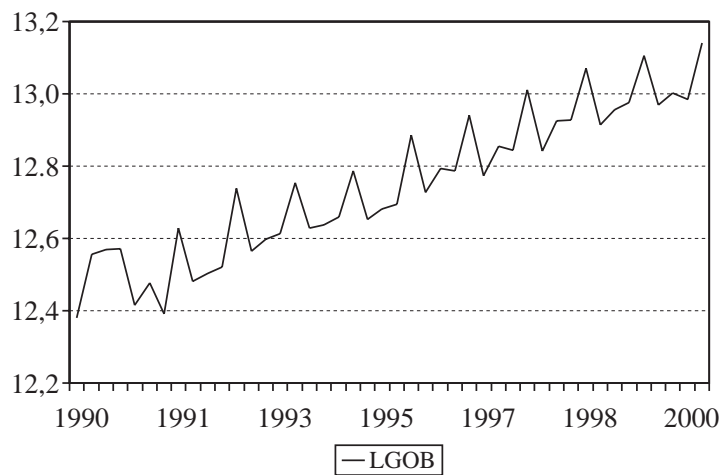

Gráfico B21: LRSTPR

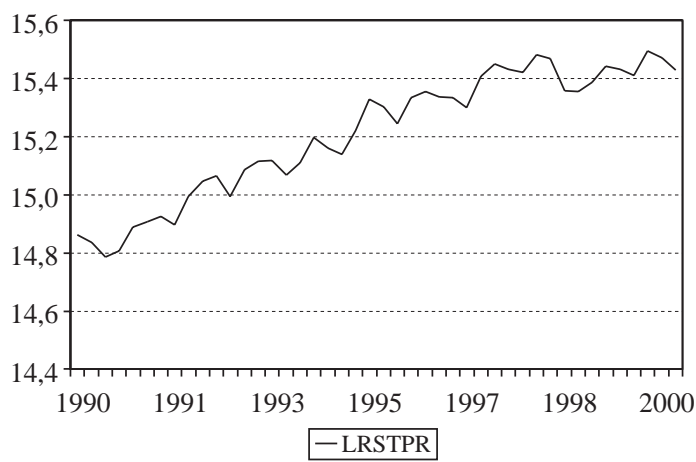

Gráfico B20: LTRIB

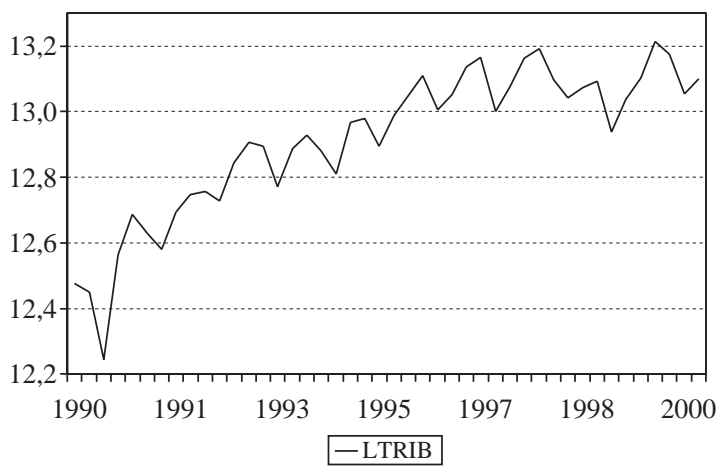

Gráfico B22: LFBKPR

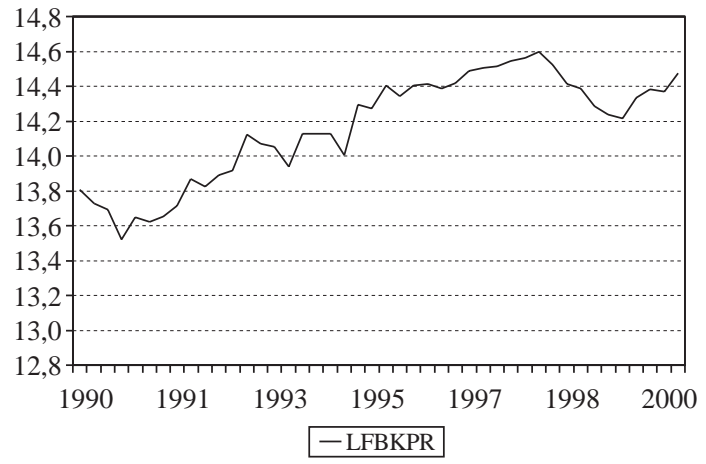

Fuente: Este conjunto de gráficos fue elaborado por los autores. 
APENDICE C

Estimaciones para el gasto privado

CUADRO C1

Chile: Cointegración para la formación bruta de capital fijo privada (LFBKPR) y del resto de la demanda agregada privada (LRSTPR) la $^{\mathrm{b}}$ Método: Mínimos cuadrados en dos etapas (1990-I - 2000-IV)

\begin{tabular}{lcc}
\hline Variable explicada & LFBKPR & LRSTPR \\
\hline Variables explicativas & & \\
Constante & 10,0561 & 12,2253 \\
& $(0,000)$ & $(0,000)$ \\
LTI & 0,4369 & -- \\
& $(0,039)$ & $(--)$ \\
FKNAY*(1-DUM98) & 1,4031 & -- \\
& $(0,034)$ & $(--)$ \\
FKNAY*DUM98 & 2,7691 & -- \\
& $(0,030)$ & $(--)$ \\
GAPHPYc & $-4,4007$ & $-1,1039$ \\
& $(0,000)$ & $(0,006)$ \\
LFIN & 0,3348 & 0,3099 \\
Tiempo & $(0,000)$ & $(0,000)$ \\
& 0,0071 & 30,39 \\
LPIB-LTRIB & $(0,040)$ & $(0,133)$ \\
& -- & 0,4679 \\
rc90*(1-DUM98) & $(--)$ & $(0,000)$ \\
\hline & -- & $-0,8976$ \\
\hline $\mathrm{R}^{2}$ corregido & $(--)$ & $(0,000)$ \\
Durbin Watson & 0,954 & 0,961 \\
Estadístico F & 2,184 & 1,693 \\
\hline & 135,381 & 243,106 \\
\hline
\end{tabular}

Fuente: Elaborado por los autores.

a Las cifras entre paréntesis corresponden a valores $\mathrm{P}$.

b Instrumentos: CFE, LFIN(-1), LOFCA, FKN(-1), GAPHPY(-1), LFBKF(-1, LPIB(-1), LTI, TIEMPO, DUM98, RC90(-1), LIBO90, SPREAD(-1), LRSTD(-1), LGOB, FKNAY(-1), LTRIB(-1), LTCR(-1), REXT, EDTCR(-1), LRSTD(-1), LGOB2, LGOBRST, LGOBFBK.

c Definido como la diferencia entre el PIB potencial representado por un filtro de Hodrick-Prescott aplicado al PIB acumulado anual, y el PIB efectivo acumulado anual.

d Véase Lehmann (1998).

Para la formación de capital fijo se incluyeron variables explicativas que se relacionan con la rentabilidad de las inversiones, como los términos de intercambio (LTI) y el gap del producto (GAPHPY), y variables que representan el efecto de condiciones de financiamiento sobre la inversión, como el flujo de capitales netos acumulado anual (FKNAY) y el valor de capitalización accionaria (LFIN). Los flujos de capitales (FKNAY) tienen un efecto positivo sobre la formación de capital, el que se hace más intenso en el período de baja de las entradas de capitales (DUM98=1), siendo también el período de menor intervención cambiaria. El resto de la demanda agregada privada abarca el consumo y la variación de inventarios. Las variables explicativas consideradas incluyen una versión del ingreso disponible privado (LPIB-LTRIB) y la profundidad accionaria (LFIN), el gap del producto (GAPHPY) y la tasa de interés real, la que afecta al resto de la demanda
CUADRO C2

Chile: Estimaciones de corrección de errores para formación de capital fijo y resto de la demanda interna privada ${ }^{a}$ Método: mínimos cuadrados ordinarios (1991-II - 2000-IV)

\begin{tabular}{|c|c|c|}
\hline Variable explicada $=>$ & DFBKPR & DRSTPR \\
\hline \multicolumn{3}{|l|}{ Variables explicativas: } \\
\hline $\begin{array}{l}\text { C } \\
\text { DTI(-1)+ DTI(-2) }\end{array}$ & 0,44155 $(0,000)$ & $\begin{array}{c}0,01399(0,014) \\
--\end{array}$ \\
\hline DTI(-5)+ DTI(-6) & & -- \\
\hline $\operatorname{Drc} 90(-1)+\operatorname{Drc} 90(-4)$ & $(0,000)$ & -- \\
\hline $\begin{array}{l}\operatorname{Drc} 90(-3)+\operatorname{Drc} 90(-4) \\
\operatorname{Drc} 90(-6)+\operatorname{Drc} 90(-7)+(\operatorname{Drc} 90(-8)\end{array}$ & $-0,981 \overline{1}^{--}(0,000)$ & $\begin{array}{c}-0,56164 \\
(0,019) \\
--\end{array}$ \\
\hline $\begin{array}{l}\operatorname{Drc90(-6)}+\operatorname{Drc} 90(-7) \\
\operatorname{Drc} 90(-5)\end{array}$ & $\begin{array}{c}-- \\
-1,8633 \\
(0,000)\end{array}$ & $\begin{array}{c}-0,37952 \\
(0,054) \\
--\end{array}$ \\
\hline $\begin{array}{l}\text { DDFKNAY(-1)+ DDFKNAY(-2) } \\
\text { DFKNAY(-5) }\end{array}$ & $\begin{array}{c}0,72855(0,000) \\
--\end{array}$ & $0,7118 \overline{7}^{-}(0,018)$ \\
\hline $\begin{array}{l}\text { DDGAPHPY(-1) } \\
\text { DGAPHPY(-1) +DGAPHPY(-7) }\end{array}$ & $\begin{array}{l}-6,7357(0,000) \\
-1,3635(0,114)\end{array}$ & $\begin{array}{l}-- \\
--\end{array}$ \\
\hline DPIB(-1) & -- & $1,10349(0,000)$ \\
\hline $\operatorname{DPIB}(-2)$ & -- & $0,85115(0,001)$ \\
\hline DTRIB $(-2)$ & -- & $\begin{array}{c}-0,22269 \\
(0,020)\end{array}$ \\
\hline $\begin{array}{l}\text { DDy(-3) } \\
\text { Dy(-1) + Dy }(-3)\end{array}$ & $\begin{array}{c}-0,35612 \\
(0,000) \\
0,29376(0,000)\end{array}$ & $\begin{array}{l}-- \\
--\end{array}$ \\
\hline $\begin{array}{l}\text { Dy }(-5)+\text { Dy }(-6) \\
\text { Dy }(-6)+\text { Dy }(-8)\end{array}$ & $0,07005(0,096)$ & $\begin{array}{c}-0,31973 \\
(0,003) \\
(0,056)\end{array}$ \\
\hline Dy $(-4)$ & -- & 0,3204 \\
\hline Dy $(-1)+$ Dy $(-2)$ & -- & $\begin{array}{c}-0,48674 \\
(0,001)\end{array}$ \\
\hline $\operatorname{RESID}(-1)$ & $\begin{array}{c}-0,72414 \\
(0,000)\end{array}$ & $\begin{array}{c}-0,63242 \\
(0,000)\end{array}$ \\
\hline $\mathrm{R}^{2}$ corregido & 0,928 & 0,781 \\
\hline Durbin Watson & 1,968 & 2,249 \\
\hline
\end{tabular}

Fuente: Elaborado por los autores.

a Las cifras entre paréntesis son valores P. Resid(-1) representa a los residuos de la correspondiente ecuación de cointegración, con un período de rezago. D representa la primera diferencia de la variable y DD la segunda. Dy (-i) es la variable explicada con $i$ rezagos.

sólo en el período de elevada disponibilidad de financiamiento externo (DUM98=0). La estimación del modelo de corrección de errores para la demanda de origen privado se presenta en el cuadro $\mathrm{C} 2$. Las variables consideradas, incluyendo la variación de la tasa de interés, de los términos de intercambio y del gap del producto, tienen los signos esperados y son significativamente distintas de cero. 
APENDICE D

Chile: Prueba de raíz unitaria de Dickey-Fuller aumentada (ADF)

\begin{tabular}{|c|c|c|c|c|}
\hline Variable & $\mathrm{ADF} / \mathrm{EGR}$ & Constante & Tendencia & Constante y tendencia \\
\hline FKN & $-5,0^{\mathrm{a}}$ & Sí & No & $-5,0^{\mathrm{a}}$ \\
\hline dFKN & $-3,3^{\mathrm{b}}$ & Sí & No & $-7,2^{\mathrm{a}}$ \\
\hline LTI & $-2,1$ & Sí & No & $-2,8$ \\
\hline dTI & $-8,8^{\mathrm{a}}$ & Sí & No & $-8,7^{\mathrm{a}}$ \\
\hline Spread & $-2,5$ & Sí & No & $-2,3$ \\
\hline dSpread & $-4,5^{\mathrm{a}}$ & Sí & No & $-4,6^{\mathrm{a}}$ \\
\hline Spread_2 2 & $-6,9^{\mathrm{a}}$ & Sí & No & $-7,4^{\mathrm{a}}$ \\
\hline dSpread_2 & $-5,7^{\mathrm{a}}$ & Sí & No & $-5,8^{\mathrm{a}}$ \\
\hline CFE & $-1,6$ & Sí & No & $-1,6$ \\
\hline dCFE & $-5,3^{\mathrm{a}}$ & Sí & No & $-5,2^{\mathrm{a}}$ \\
\hline LTCR & $-2,1$ & Sí & No & $-0,7$ \\
\hline dLTCR & $-6,6^{\mathrm{a}}$ & Sí & No & $-7,1^{\mathrm{a}}$ \\
\hline RC90 & $-3,3$ & Sí & No & $-3,2$ \\
\hline DRC90 & $-5,4^{\mathrm{a}}$ & Sí & No & $-4,2^{\mathrm{a}}$ \\
\hline LIBO90 & $-2,1$ & Sí & No & $-2,9$ \\
\hline dLIBO90 & $-2,5^{\mathrm{b}}$ & No & No & $-2,5$ \\
\hline REXT & $-2,3$ & Sí & No & $-2,2$ \\
\hline dREXT & $-5,8^{\mathrm{a}}$ & No & No & $-5,8^{\mathrm{a}}$ \\
\hline EdTCR & $-2,7$ & Sí & No & $-2,7$ \\
\hline dEdTCR & $-7,8^{\mathrm{a}}$ & No & No & $-7,7^{\mathrm{a}}$ \\
\hline LFIN & $-2,0$ & Sí & No & $-1,1$ \\
\hline dFIN & $-3,0^{\mathrm{b}}$ & No & No & $-3,5^{\mathrm{a}}$ \\
\hline LOFCA & $-6,5^{\mathrm{a}}$ & Sí & No & $-6,4^{a}$ \\
\hline dLOFCA & $-11,5^{\mathrm{a}}$ & No & No & $-11,4^{\mathrm{a}}$ \\
\hline LPIB & $-2,7$ & Sí & No & $-2,1$ \\
\hline $\mathrm{dPIB}^{\mathrm{a}}$ & $-1,9$ & Sí & No & $-2,9$ \\
\hline LDDA & $-0,9$ & Sí & No & $-1,5$ \\
\hline dDDA & $-6,5^{\mathrm{a}}$ & Sí & No & $-6,6^{\mathrm{a}}$ \\
\hline LFBKPR & $-1,1$ & Sí & No & $-2,7$ \\
\hline dFBKPR & $-8,0^{\mathrm{a}}$ & Sí & No & $-7,9^{\mathrm{a}}$ \\
\hline LRSTPR & $-2,0$ & Sí & No & $-1,9$ \\
\hline dRSTPR & $-8,5^{\mathrm{a}}$ & Sí & No & $-4,9^{\mathrm{a}}$ \\
\hline FKNCP & $-4,6^{\mathrm{a}}$ & Sí & No & $-4,6^{\mathrm{a}}$ \\
\hline dFKNCP & $-6,6^{a}$ & Sí & No & $-6,6^{a}$ \\
\hline FKNMYLP & $-4,8^{\mathrm{a}}$ & Sí & No & $-4,8^{\mathrm{a}}$ \\
\hline dFKNMYLP & $-12,5^{\mathrm{a}}$ & Sí & No & $-12,4^{\mathrm{a}}$ \\
\hline FKNAY & $-1,9$ & Sí & No & $-2,2$ \\
\hline dFKNAY & $-4,9^{\mathrm{a}}$ & Sí & No & $-5,0^{\mathrm{a}}$ \\
\hline GAPHPY & $-4,4^{\mathrm{a}}$ & Sí & No & $-4,2^{\mathrm{a}}$ \\
\hline dGaphpy & $-4,5^{\mathrm{a}}$ & Sí & No & $-4,4^{\mathrm{a}}$ \\
\hline LTRIB & $-3,5^{\mathrm{b}}$ & Sí & No & $-1,9$ \\
\hline dTrib & $-3,3^{\mathrm{b}}$ & Sí & No & $-4,0^{\mathrm{a}}$ \\
\hline
\end{tabular}

Fuente: Elaborado por los autores.

a Rechazado al 1\%. b Rechazado al $5 \%$.

a Usando el test de Phillips-Perron, la hipótesis de raíz unitaria se rechaza al 1\% de significancia, incluyendo constante y tendencia o sólo constante. 
APENDICE E

Prueba de raíz unitaria de Engle y Granger para residuos (EGR) ${ }^{\mathrm{a}}$ (Sin constante ni tendencia)

\begin{tabular}{lc}
\hline Variable & EGR \\
\hline RESIDFKN & $-7,0^{\mathrm{a}}$ \\
RESIDFKNCP & $-4,2^{\mathrm{a}}$ \\
RESIDFKNMYLP & $-5,5^{\mathrm{a}}$ \\
RESIDFKBPR & $-6,4^{\mathrm{a}}$ \\
RESIDRSTD & $-5,6^{\mathrm{a}}$ \\
RESIDSpread 2 & $-7,4^{\mathrm{a}}$ \\
RESIDrC90 & $-4,7^{\mathrm{a}}$ \\
RESIDLTCR & $-2,0$
\end{tabular}

Fuente: Elaborado por los autores.

a Rechazado al 1\%. Valor crítico del EGR: al 1\%, -3,73; al 5\%, -2,91.

b Véase Enders (1995), p. 383.

APENDICE F

Chile: Matriz de caracterización de variables ${ }^{a}$

(1990-I a 1997-IV)

\begin{tabular}{|c|c|c|c|c|c|c|}
\hline & $\begin{array}{c}\text { Crecimiento } \\
\text { mundial }\end{array}$ & $\begin{array}{c}\text { Oferta } \\
\text { capitales }\end{array}$ & $\begin{array}{l}\text { Influjos } \\
\text { capitales }\end{array}$ & $\begin{array}{l}\text { Precio } \\
\text { cobre }\end{array}$ & $\begin{array}{l}\text { Términos } \\
\text { intercambio }\end{array}$ & $\begin{array}{l}\text { Cta. Cte. } \\
\text { tendencia }\end{array}$ \\
\hline Crecimiento mundial & $2,15 / 0,91$ & 0,26 & 0,23 & 0,5 & 0,52 & 0,057 \\
\hline Oferta capitales & 0 & $68,62 / 70,7$ & 0,02 & $-0,03$ & 0,24 & $-0,35$ \\
\hline Flujos netos & $2==>1$ & 0 & $0,24 / 0,05$ & 0,25 & 0,16 & $-0,345$ \\
\hline Precio cobre & 0 & 0 & 0 & $106,21 / 22,76$ & 0,85 & $-0,014$ \\
\hline Términos intercamio & 0 & $1==>2$ & 0 & $2==>1$ & $125,27 / 11,48$ & $-0,089$ \\
\hline Cta. Cte. tendencia & 0 & 0 & $2==>1$ & 0 & 0 & $0,76 / 0,88$ \\
\hline
\end{tabular}

Fuente: Elaborado por los autores.

a Sobre la diagonal aparece la media y la desviación estándar de cada variable. En las celdas de la parte superior de la diagonal se presenta el coeficiente de correlación entre las variables. En la parte inferior de la matriz se indica el resultado del test de causalidad de Granger. La identificación 1 corresponde a la variable que aparece en la fila y la identificación 2 a la de la columna.

Se desprende de los resultados que el crecimiento mundial causa los flujos netos de capitales a Chile, que los términos de intercambio causan la oferta de capitales, y que la afluencia de capitales causa la cuenta corriente de tendencia (o el gasto). La oferta de capitales responde positivamente a los términos de intercambio, pero no así al precio del cobre. 
APENDICE G

CUADRO G1

Cointegración de flujo de capitales netos totales ${ }^{a-b}$

Especificaciones alternativas

Método: Mínimos cuadrados en dos etapas

(1991-I - 2000-IV)

\begin{tabular}{|c|c|c|c|c|c|}
\hline Variable explicada & $\begin{array}{l}\text { FKN } \\
(1)\end{array}$ & $\begin{array}{l}\text { FKN } \\
\text { (2) }\end{array}$ & $\begin{array}{l}\text { FKN } \\
(3)\end{array}$ & $\begin{array}{l}\text { FKN } \\
\text { (4) }\end{array}$ & $\begin{array}{c}\text { FKN } \\
(5)\end{array}$ \\
\hline \multicolumn{6}{|l|}{ Variables explicativas: } \\
\hline Constante & $\begin{array}{c}13104,97 \\
(0,101)\end{array}$ & $\begin{array}{c}9336,26 \\
(0,161)\end{array}$ & $\begin{array}{c}13616,61 \\
(0,107)\end{array}$ & $\begin{array}{c}8263,05 \\
(0,384)\end{array}$ & $\begin{array}{c}7795,05 \\
(0,377)\end{array}$ \\
\hline LTI & $\begin{array}{c}-2671,56 \\
(0,139)\end{array}$ & $\begin{array}{c}-1819,65 \\
(0,220)\end{array}$ & $\begin{array}{c}-3102,50 \\
(0,108)\end{array}$ & $\begin{array}{c}-1554,11 \\
(0,489)\end{array}$ & $\begin{array}{c}-1433,58 \\
(0,464)\end{array}$ \\
\hline LDDA-LPIB & $\begin{array}{c}16503,11 \\
(0,000)\end{array}$ & $\begin{array}{c}13788,89 \\
(0,001)\end{array}$ & $\begin{array}{c}16457,78 \\
(0,001)\end{array}$ & $\begin{array}{c}17725,94 \\
(0,001)\end{array}$ & $\begin{array}{c}18099,08 \\
(0,000)\end{array}$ \\
\hline Spread & $\begin{array}{c}2920,02 \\
(0,443)\end{array}$ & $\begin{array}{l}-- \\
(--)\end{array}$ & $\begin{array}{c}3233,07 \\
(0,419)\end{array}$ & $\begin{array}{c}4285,85 \\
(0,355)\end{array}$ & $\begin{array}{c}3987,97 \\
(0,333)\end{array}$ \\
\hline Spread_2 & $\begin{array}{l}-- \\
(--)\end{array}$ & $\begin{array}{l}-360,21 \\
(0,720)\end{array}$ & $\begin{array}{l}-- \\
(--)\end{array}$ & $\begin{array}{l}-- \\
(--)\end{array}$ & $\begin{array}{l}-- \\
(--)\end{array}$ \\
\hline CFE & $\begin{array}{c}-26282,12 \\
(0,054)\end{array}$ & $\begin{array}{c}-26811,84 \\
(0,024)\end{array}$ & $\begin{array}{c}-26927,32 \\
(0,067)\end{array}$ & $\begin{array}{c}2011,64 \\
(0,881)\end{array}$ & $\begin{array}{l}-- \\
(--)\end{array}$ \\
\hline DUM98 & $\begin{array}{c}-1887,17 \\
(0,000)\end{array}$ & $\begin{array}{c}-1932,33 \\
(0,000)\end{array}$ & $\begin{array}{l}-- \\
(--)\end{array}$ & $\begin{array}{c}-- \\
(--)\end{array}$ & $\begin{array}{l}-- \\
(--)\end{array}$ \\
\hline LOFCA (1-DUM98) & $\begin{array}{l}-- \\
(--)\end{array}$ & $\begin{array}{l}-- \\
(--)\end{array}$ & $\begin{array}{l}378,53 \\
(0,002)\end{array}$ & $\begin{array}{l}-- \\
(--)\end{array}$ & $\begin{array}{l}-- \\
(--)\end{array}$ \\
\hline Tiempo & $\begin{array}{c}33,45 \\
(0,085)\end{array}$ & $\begin{array}{c}35,58 \\
(0,060)\end{array}$ & $\begin{array}{c}22,71 \\
(0,225)\end{array}$ & $\begin{array}{l}-24,05 \\
(0,103)\end{array}$ & $\begin{array}{l}-25,31 \\
(0,034)\end{array}$ \\
\hline $\mathrm{R}^{2}$ corregido & 0,419 & 0,486 & 0,358 & 0,135 & 0,159 \\
\hline Estadístico Durbin Watson & 2,200 & 2,269 & 2,072 & 1,699 & 1,681 \\
\hline Estadístico F & 7,238 & 7,389 & 6,232 & 3,789 & 4,866 \\
\hline
\end{tabular}

Fuente: Elaborado por los autores.

a Las cifras entre paréntesis son valores $\mathrm{P}$.

b Instrumentos: CFE, LFIN(-1), LOFCA, FKN(-1), GAPHPY(-1), LFBKF(-1), LPIB(-1), LTI, TIEMPO, DUM98, rc90(-1), LIBO90, SPREAD(-1), LRSTD(-1), LGOB, FKNAY(-1), LTRIB(-1), LTCR(-1), REXT, EDTCR(-1).

Todas las especificaciones alternativas presentan el efecto negativo y estadísticamente significativo del CFE sobre los flujos de capitales netos totales. La única excepción se da cuando se excluyen de la especificación variables que representan la intensificación de la oferta de capitales producida durante el período de aplicación del encaje.

Además de las cinco especificaciones alternativas se presentan los resultados de la prueba de restricción de coeficientes. En el cual el efecto del spread se iguala con el del CFE, sólo que con el signo contrario. La prueba se aplica a la especificación (1), que es una versión sin restricciones de la ecuación de cointegración para los FKN usada en este trabajo y la restricción no es rechazada por los datos al 10\% de significancia. También se presenta la prueba de exclusión del CFE aplicada a la especificación (1), la cual es rechazada por los datos al $5 \%$ de significancia, y la prueba de exclusión de CFE y DUM98, la que se rechaza al 1\% de significancia. 
CUADRO G2

Tests de restricciones y exclusión de variables en la cointegración de los flujos de capitales netos totales

Test de Wald:

Ecuación: EQFKN

\begin{tabular}{lccc}
\hline Test estadístico & Valor & df & Probabilidad \\
Estadístico F & 2.406231 & $(1,33)$ & 0.1304 \\
Chi cuadrado & 2.406231 & 1 & 0.1209 \\
\hline Resumen de hipótesis nula: & & & \\
\hline Restricción normalizada (=0) & Valor & Error estándar & \\
$\mathrm{C}(4)+\mathrm{C}(5)$ & -23362.10 & 15060.63 & \\
\hline
\end{tabular}

Variables redundantes: $\mathrm{CFE}$

\begin{tabular}{lll}
\hline Estadístico F & 4.160857 & Probabilidad
\end{tabular}

Variable dependiente: FKN

Método: Mínimos cuadrados de dos etapas

Muestra: 1991:1 2000:4

Observaciones incluidas: 40

\begin{tabular}{|c|c|c|c|c|}
\hline Variable & Coeficiente & Error estándar & Estadístico t & Probabilidad \\
\hline $\mathrm{C}$ & 15881.50 & 8179.707 & 1.941573 & 0.0605 \\
\hline LDDA-LPIB & 13412.14 & 4091.269 & 3.278235 & 0.0024 \\
\hline LTI & -3426.204 & 1837.548 & -1.864552 & 0.0709 \\
\hline SPREAD & 5919.967 & 3844.308 & 1.539931 & 0.1328 \\
\hline DUM98 & -1350.852 & 425.1714 & -3.177193 & 0.0032 \\
\hline TIEMPO & 28.58302 & 19.70826 & 1.450306 & 0.1561 \\
\hline $\mathrm{R}^{2}$ & 0.436849 & \multicolumn{2}{|c|}{ Media de la variable dependiente } & 724.1099 \\
\hline $\mathrm{R}^{2}$ ajustado & 0.354033 & \multicolumn{2}{|c|}{ Desviación estándar de la variable dependiente } & 758.3639 \\
\hline Error estándar de la regresión & 609.5127 & \multicolumn{2}{|c|}{ Suma de los cuadrados de los residuos } & 12.631 .195 \\
\hline Estadístico F & 6.935445 & \multicolumn{2}{|c|}{ Estadístico Durbin-Watson } & 2.109922 \\
\hline $\begin{array}{l}\text { Probabilidad } \\
\text { (estadístico F) }\end{array}$ & 0.000147 & & & \\
\hline
\end{tabular}

Variables redundantes: CFE DUM98

\begin{tabular}{|c|c|c|c|c|}
\hline \multirow{2}{*}{$\begin{array}{l}\text { Estadístico F } \\
\text { Variable }\end{array}$} & \multirow{2}{*}{$\begin{array}{c}7.782162 \\
\text { Coeficiente }\end{array}$} & \multicolumn{2}{|c|}{ Probabilidad } & \multirow{2}{*}{$\begin{array}{c}0.001703 \\
\text { Probabilidad }\end{array}$} \\
\hline & & Error estándar & Estadístico t & \\
\hline $\mathrm{C}$ & 7609.241 & 8822.429 & 0.862488 & 0.3943 \\
\hline LDDA-LPIB & 17984.64 & 4357.349 & 4.127427 & 0.0002 \\
\hline LTI & -1391.464 & 1959.591 & -0.710079 & 0.4824 \\
\hline SPREAD & 3807.827 & 4307.973 & 0.883902 & 0.3828 \\
\hline TIEMPO & -25.22153 & 11.47011 & -2.198891 & 0.0346 \\
\hline $\mathrm{R}^{2}$ & 0.249573 & \multicolumn{2}{|c|}{ Media de la variable dependiente } & 724.1099 \\
\hline $\mathrm{R}^{2}$ ajustado & 0.163810 & \multicolumn{2}{|c|}{ Desviación estándar de la variable dependiente } & 758.3639 \\
\hline Error estándar de la regresión & 693.4739 & \multicolumn{2}{|c|}{ Suma de los cuadrados de los residuos } & 16.831 .710 \\
\hline Estadístico F & 4.747603 & \multicolumn{2}{|c|}{ Estadístico Durbin-Watson } & 1.681684 \\
\hline Probabilidad (estad. F) & 0.003633 & & & \\
\hline
\end{tabular}


APENDICE H

Modelos de corrección de errores: flujos de capitales netos totales

CUADRO HI

Especificaciones alternativas

Método: mínimos cuadrados ordinarios

(1991-II - 2000-IV)

\begin{tabular}{|c|c|c|c|}
\hline Variable explicada & $\begin{array}{l}\text { DFKN } \\
(1)\end{array}$ & $\begin{array}{l}\text { DFKN } \\
(2)\end{array}$ & $\begin{array}{l}\text { DFKN } \\
(3)\end{array}$ \\
\hline \multicolumn{4}{|l|}{ Variables explicativas: } \\
\hline DCFE(-4) & $\begin{array}{c}-20628,87 \\
(0,114)\end{array}$ & $\begin{array}{c}-20547,31 \\
(0,016)\end{array}$ & $\begin{array}{c}-21714,33 \\
(0,007)\end{array}$ \\
\hline $\operatorname{DREXT}(-4)$ & $\begin{array}{c}-20796,53 \\
(0,014)\end{array}$ & $\begin{array}{c}-20547,31 \\
(0,016)\end{array}$ & $\begin{array}{c}-21714,33 \\
(0,007)\end{array}$ \\
\hline DSPREAD $(-3)$ & $\begin{array}{r}4311,87 \\
(0,011)\end{array}$ & $(--)$ & $\begin{array}{c}6891,60 \\
(0,007)\end{array}$ \\
\hline DTI(-3)+DTI(-4) & $\begin{array}{c}-2837,73 \\
(0,024)\end{array}$ & $\begin{array}{c}-2714,69 \\
(0,054)\end{array}$ & $\begin{array}{c}-4226,93 \\
(0,003)\end{array}$ \\
\hline $\operatorname{DLOFCA}(-2)+\operatorname{DLOFCA}(-4)$ & $\begin{array}{c}51,44 \\
(0,100)\end{array}$ & $\begin{array}{l}72,39 \\
(0,037)\end{array}$ & $\begin{array}{c}71,69 \\
(0,026)\end{array}$ \\
\hline DDDA(-4)-DPIB(-4) & $\begin{array}{l}9674,33 \\
(0,0003)\end{array}$ & $\begin{array}{c}9556,90 \\
(0,002)\end{array}$ & $\begin{array}{c}11302,25 \\
(0,000)\end{array}$ \\
\hline $\operatorname{DFKN}(-4)$ & $\begin{array}{l}0,35347 \\
(0,0015)\end{array}$ & $\begin{array}{c}0,289513 \\
(0,008)\end{array}$ & $\begin{array}{c}0,37741 \\
(0,000)\end{array}$ \\
\hline RESIDY(-1) & $\begin{array}{c}-0,80899 \\
(0,000)\end{array}$ & $\begin{array}{c}-0,77950 \\
(0,000)\end{array}$ & $\begin{array}{c}-0,63882 \\
(0,000)\end{array}$ \\
\hline $\mathrm{R}^{2}$ corregido & 0,788 & 0,718 & 0,751 \\
\hline Durbin-Watson & 2,081 & 2,186 & 2,246 \\
\hline
\end{tabular}

Fuente: Elaborado por los autores.

a Las cifras entre paréntesis son valores P. Residy (-1) representa los residuos de la correspondiente ecuación de cointegración, con un período de rezago.

La especificación (1) presenta una versión alternativa del modelo de corrección de errores asociada a la relación de cointegración para FKN seleccionada. La segunda columna presenta un modelo de corrección de errores basado en la especificación alternativa (4) para la cointegración de FKN, en que se usa el spread efectivo (Spread_2) en lugar del spread esperado. La tercera se basa en la especificación de cointegración de FKN (5) en la que se incluye LOFCA en lugar de Dum98 para representar la oferta de capitales.
La primera restricción consiste en excluir del modelo de corrección de errores, seleccionando todas las variables asociadas al arbitraje. Se rechaza esta restricción al 1\% de significancia de acuerdo con las pruebas $\mathrm{F}$ y la razón de verosimilitud. La segunda restricción consiste en excluir sólo las variables asociadas al encaje; en este caso también se rechaza la restricción al $1 \%$ de significancia de acuerdo con las pruebas F y la razón de verosimilitud. 
CUADRO H2

Test de restricciones en la corrección de errores para FKN

Variables redundantes: DCFE(-4) DCFE(-7) DREXT(-5)

\begin{tabular}{|c|c|c|c|c|}
\hline $\begin{array}{l}\text { Estadístico } \mathrm{F} \\
\text { Log razón de verosimilitud }\end{array}$ & $\begin{array}{l}12.55910 \\
34.92271\end{array}$ & $\begin{array}{l}\text { Probabilidad } \\
\text { Probabilidad }\end{array}$ & \multicolumn{2}{|c|}{0.000046} \\
\hline \multicolumn{5}{|l|}{$\begin{array}{l}\text { Variable dependiente: DFKN } \\
\text { Método: Mínimos cuadrados } \\
\text { Muestra: 1992-II 2001-I }\end{array}$} \\
\hline Variable & Coeficiente & Error estándar & Estadístico t & Probabilidad \\
\hline $\mathrm{C}$ & -14.07508 & 64.33351 & -0.218783 & 0.8285 \\
\hline DTI(-3)+DTI(-4) & -1372.601 & 1104.481 & -1.242757 & 0.2250 \\
\hline DTI(-6) & -5480.374 & 1309.262 & -4.185850 & 0.0003 \\
\hline DTI(-7)+DTI(-8) & 3100.855 & 1130.278 & 2.743444 & 0.0109 \\
\hline $\operatorname{DLOFCA}(-2)+\operatorname{DLOFCA}(-4)$ & 64.93306 & 26.13234 & 2.484778 & 0.0197 \\
\hline $\operatorname{DLOFCA}(-8)$ & 71.60060 & 39.47195 & 1.813961 & 0.0812 \\
\hline $\operatorname{DDDA}(-4)-\operatorname{DPIB}(-4)$ & 10852.28 & 2684.125 & 4.043136 & 0.0004 \\
\hline DFKN(-4) & 0.304481 & 0.083557 & 3.643988 & 0.0012 \\
\hline $\operatorname{DFKN}(-7)+\operatorname{DFKN}(-8)$ & -0.156841 & 0.097817 & -1.603423 & 0.1209 \\
\hline RESIDFKN(-1) & -0.828273 & 0.146451 & -5.655622 & 0.0000 \\
\hline $\mathrm{R}^{2}$ & 0.885404 & Media de la $v$ & endiente & -15.16610 \\
\hline $\mathrm{R}^{2}$ ajustado & 0.845736 & Desviación estándar & ble dependiente & 972.2218 \\
\hline Error estándar de la regresión & 381.8540 & Criterio de inf & le Akaike & 14.95809 \\
\hline Suma de los cuadrados de los residuos & 3.791 .125 & Criteric & & 15.39795 \\
\hline Log verosimilitud & -259.2456 & Esta & & 22.32045 \\
\hline Estadístico Durbin-Watson & 1.912767 & Probabilida & ico F) & 0.000000 \\
\hline \multicolumn{5}{|l|}{ Variables redundantes: DCFE(-4) DCFE(-7) } \\
\hline Estadístico F & 8.064264 & Probabilidad & 0.0022 & \\
\hline Log razón de verosimilitud & 19.12887 & Probabilidad & 0.0000 & \\
\hline
\end{tabular}

Variable dependiente: DFKN

Método: Mínimos cuadrados

Muestra: 1992-II 2001-I

\begin{tabular}{|c|c|c|c|c|}
\hline Variable & Coeficiente & Error estándar & Estadístico t & Probabilidad \\
\hline $\mathrm{C}$ & -52.82989 & 53.71039 & -0.983606 & 0.3347 \\
\hline DREXT(-5) & -23913.63 & 6444.825 & -3.710517 & 0.0010 \\
\hline DTI(-3)+DTI(-4) & -1482.778 & 904.9873 & -1.638451 & 0.1139 \\
\hline DTI $(-6)$ & -5957.520 & 1079.886 & -5.516802 & 0.0000 \\
\hline DTI(-7)+DTI(-8) & 2302.837 & 950.2834 & 2.423316 & 0.0230 \\
\hline $\operatorname{DLOFCA}(-2)+\operatorname{DLOFCA}(-4)$ & 51.37420 & 21.71047 & 2.366334 & 0.0260 \\
\hline $\operatorname{DLOFCA}(-8)$ & 88.04781 & 32.62752 & 2.698575 & 0.0123 \\
\hline $\operatorname{DDDA}(-4)-\operatorname{DPIB}(-4)$ & 10517.75 & 2199.977 & 4.780848 & 0.0001 \\
\hline $\operatorname{DFKN}(-4)$ & 0.287082 & 0.068588 & 4.185573 & 0.0003 \\
\hline $\operatorname{DFKN}(-7)+\operatorname{DFKN}(-8)$ & -0.202594 & 0.081049 & -2.499642 & 0.0194 \\
\hline RESIDFKN $(-1)$ & -0.927187 & 0.122861 & -7.546624 & 0.0000 \\
\hline $\mathrm{R}^{2}$ & 0.926101 & \multicolumn{2}{|c|}{ Media de la variable dependiente } & -15.16610 \\
\hline $\mathrm{R}^{2}$ ajustado & 0.896542 & \multicolumn{2}{|c|}{ Desviación estándar de la variable dependiente } & 972.2218 \\
\hline Error estándar de la regresión & 312.7143 & \multicolumn{2}{|c|}{ Criterio de información de Akaike } & 14.57492 \\
\hline $\begin{array}{l}\text { Suma de los cuadrados de los } \\
\text { residuos }\end{array}$ & 2.444 .755 & \multicolumn{2}{|c|}{ Criterio de Schwarz } & 15.05878 \\
\hline Log verosimilitud & -251.3486 & \multicolumn{2}{|c|}{ Estadístico F } & 31.33011 \\
\hline Estadístico Durbin-Watson & 2.156734 & \multicolumn{2}{|c|}{ Probabilidad (estadístico F) } & 0.000000 \\
\hline
\end{tabular}

